\title{
Sharon Shah Palace (Baku - Azerbaijan)
}

\author{
Shehata Elsayed Shehata Ibrahim \\ PhD researcher, Department of Civilizations, Faculty of Higher Asian \\ Studies, Zagazig University
}

\begin{abstract}
:
The research aims to introduce one of the important architectural and archaeological landmarks in the city of Baku, which is the Palace of Sharon Shah, which helps to strengthen the bonds of the relationship between the Islamic peoples and create an automatic and realistic unity, and to achieve an "important human" goal of blending and meeting the civilization of Islamic peoples, highlighting the historical, archaeological, architectural and tourism status The palace of Sharon Shah, which was the seat of the rule of the longest-lived state in Islamic history, the state of Sharon Shah.

Clarify the role of historical monuments, whose roots extend back many centuries, in cultural tourism, and work to raise the level of performance in them; In order to increase the demand for it by all classes of societies that seek types of tourism that play their role in accordance with human values and etiquette in acquaintance between peoples and nations.

The importance of research The city of Baku is one of the most important historical and religious cities in the Republic of Azerbaijan. In
\end{abstract}


which the palace of Sharon Shah, the subject of research, and other tourist attractions such as the Maiden's Tower are located.

يهدف البحث إلى التعريف بأحد المعالم المعمارية والأثرية الهامة في مدينة باكو وهو قصر شروان شاه، مما يساعد علي توثيق أواصر العلاقة بين الثعوب الإسلامية وخلق وحدة تلقائية وواقعية، وتحقيق هدفاً " إنسانياً مهماً" هو تمازج حضارة الثعوب الإسلامية والتقائها ، إبراز المكانة التاريخية والأثرية والمعمارية والسياحية لقصر شروان شاه، الذي كان مقراً لحكم أطول دوله عمراً في التاريخ الاسلامي وهي دولة شروان شاه.

توضيح دور المعالم التاريخية التي تمتد جذورها لقرون عديدة في السياحة الثقافية ، والعمل على رفع مستوى الأداء فيها ؛ لكي يزداد الإقبال عليها من قبل كافة طبقات المجتمعات التي تسعي إلى أنواع السياحة التي تؤدي دورها وفق القيم الإنسانية وآدابها في التعارف ما بين الثعوب والأمم. أهمية البحث تعد مدينة باكو واحدة من أهم المدن التاريخية والدينية في جمهورية أذربيجان، وتحتل مكانة ومنزلة سامية لما فيها من أماكن ومقومات جذب سياحية ذات شهرة محلية وإقليمية وعالمية، ويتوافد إليها ملايين السائحين والزوار من كل دول العالم لزيارة المعالم التاريخية والأثرية الموجودة بها مثل المدينة القديمة التي يوجد بها قصر شروان شاه موضوع البحث وغيره من المعالم السياحية مثل برج

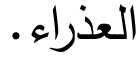


تقع جمهورية أذربيجان الديمقرطية ( لوحات 1-2-3 ) على الثاطئ الغربي

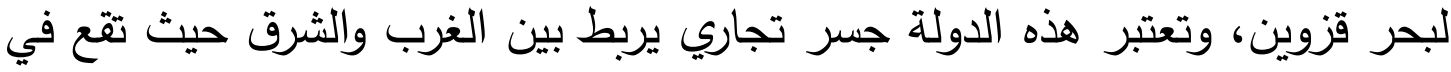
منطقة أوراسيا التي تضم شمال غرب قارة أسيا وجنوب شرق أوروبا، يحدها بحر قزوين من الثرق ، ومنطقة داغستان الروسية من الثمال ، وجورجيا من الثمال

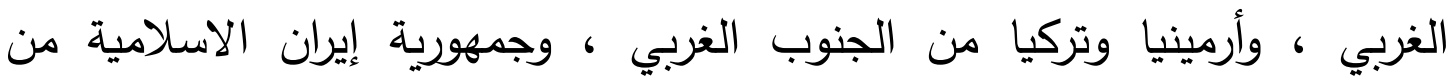

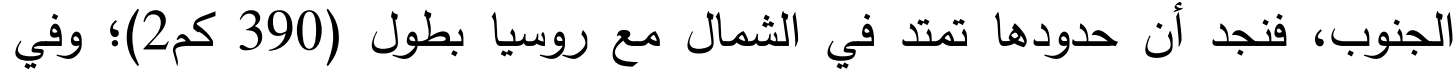
الجنوب مع إيران بطول (756 كم2)؛ وفي الجنوب الغربي مع تركيا (13 كم2) ؛ وحدودها في الثمال الغربي مع جورجيا بطول (480 كم2)؛ كما تمتد حدودها في الغرب مع أرمينيا بطول (1007 كم2)، وقد ساعد موقع أذربيجان المتميز أن تكون

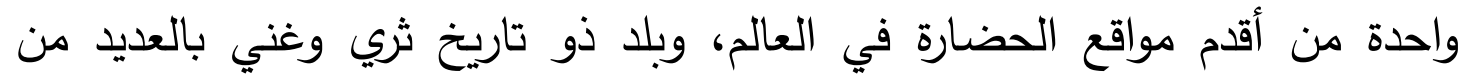

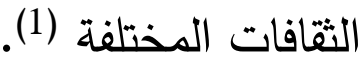

تقع مدينة باكو على شاطئ بحر قزوين الغربي ، جنوب شرق شبه جزيرة أبشيرون التي تتمتع بظروف طبيعية وجغرافية مميزة ، وتعتبر باكو أكبر مدن بكاني

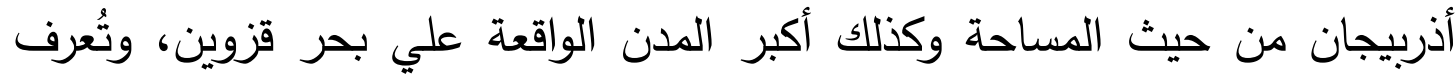
عاصمة أذربيجان ( باكو) ( لوحة 4 ) ، بأنها واحدة من أقدم الددن وأكثرها ثقافة في

(1) Dilgam Yunis Ismailov:History of Azerbaijan, Azmiu npm,Baku, 2017,p11. 
العالم، وارتبطت تاريخيا وجغرافيا بالعديد من دول العالم المختلفة، ولعبت دوراً كبيراً في الحياة الاقتصادية والسياسية والثقافية لشعوب دول شرق ووسط أسيا لعدة قرون ، مما يؤكد علي أهمية هذه المدينة تاريخيا وجغرافيا خلال العصور المختلفة (2) . تبلغ مساحة باكو 2014 كم2، بينما يبلغ عدد السكان الحالي في عام 1442هـ/ 2021م وفقاً لأخر احصائية في شهر يناير 2 مليون و 293 الف نسمة بمعدل 1072 نسمة لكل كم2؛ وتنقسم مدينة باكو الي 12 منطقة ادارية ومنها منطقة نظامي ، الخزر ، والمدينة القديمة؛ وتعتبر باكو المركز الثقافي والعلمي

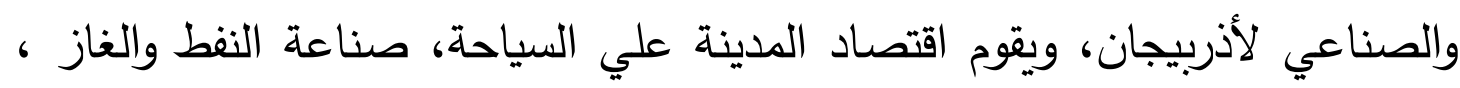
الهندسة الميكانيكية، وانتاج الاغذية والالبان وغيرهان(3).

$$
\begin{aligned}
& \text { أهداف البحث: : } \\
& \text { يهدف البحث إلى : }
\end{aligned}
$$

التعريف بأحد المعالم المعمارية والأثرية الهامة في مدينة باكو وهو قصر شروان شاه، مما يساعد علي توثيق أواصر العلاقة بين الثعوب الإسلامية وخلق وحدة تلقائية وواقعية، وتحقيق هدفاً " إنسانياً مهماً" هو تمازج حضارة الثعوب الإسلامية والتقائها .

المساعدة في تنشيط حركة السياحة وخاصة بالمعالم الأثرية السياحية الإسلامية في أذربيجان، من خلال تسليط الضوء على مدينة باكو العاصمة ومعالمها السياحية.

$\left(^{2}\right)$ FəRHADOĞLU Kamil : BAKI. İÇəRİ̧̧HӘR. BAKI,2006, s3.

$\left(^{3}\right)$ https://president.az/president/biography. 
إبراز المكانة التاريخية والأثرية والمعمارية والسياحية لقصر شروان شاه، الذي كان مقراً لحكم أطول دوله عمراً في التاريخ الاسلامي وهي دولة شروان شاه.

إبراز الأهمية الحضارية والسياحية لمدينة باكو والتعريف بالمقومات السياحية الموجودة بالمدينة مثل قصر شروان شاه. توضيح دور المعالم التاريخية التي تمتد جذورها لقرون عديدة في السياحة الثقافية ، والعمل على رفع مستوى الأداء فيها ؛ لكي يزداد الإقبال عليها من قبل كافة طبقات المجتمعات التي تسعي إلى أنواع السياحة التي تؤدي دورها وفق القيم الإنسانية وآدابها في التعارف ما بين الثعوب

$$
\text { أهمية البحث: : }
$$

تعد مدينة باكو واحدة من أهم المدن التاريخية والدينية في جمهورية أذربيجان، وتحتل مكانة ومنزلة سامية لما فيها من أماكن ومقومات جذب سياحية ذات شهرة محلية وإقليمية وعالمية، ويتوافد إليها ملايين السائحين والزوار من كل دول العالم لزيارة المعالم التاريخية والأثرية الموجودة بها مثل المدينة القديمة التي يوجد بها قصر شروان شاه موضوع البحث وغيره من المعالم السياحية مثل برج العذراء. وتكمن أهمية هذه الدراسة من خلال : 
إبراز الأهمية الحضارية والسياحية للمدينة بما تفسحه من فرص للاتصال والتعارف بين الثعوب من مختلف الأجناس والأديان

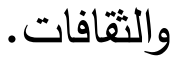

إبراز المكانة السياحية والتاريخية والاثرية لقصر شروان

دراسة المعالم التاريخية الأثرية مثل قصر شروان شاه، يعتبر قوة فعالة من شأنها تعزيز التقارب والتفاهم والسلام بين شعوب

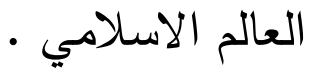

معرفة المشاكل والمعوقات التي تحول دون استغلال تلك المعالم السياحية بالمستوى المطلوب سواء كان على المستوى المحلى أو

$$
\text { منهج البحث: : }
$$

تم استخدام عدة طرق علمية لجمع البيانات والمعلومات فكان

$$
\text { أنسب المناهج التي تم الاعتماد عليها في هذا البحث : }
$$

1- المنهج الوصفي الذي تم اللجوء إليه في النطاق النظري والمنهج التحليلي للأحداث التاريخية الهامة في هذه الفترة.

2- المنهج التاريخي والذى يقوم بتتبع الحقائق الزمنية والمكانية

عبر الفترات التاريخية المختلفة وتوثيقها تاريخياً.

لذا تم الاعتماد على قاعدة التكامل المنهجي في البحث والتي تقوم على الجمع بين أكثر من منهج وفقاً لمنهج البحث العلمي. 


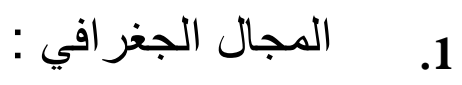

تمت دراسة الأهمية التاريخية والاثرية والسياحية لقصر شروان شاه،

الذي يقع في مدينة باكو، والتي تعد من أقدم مراكز الحضارة الإنسانية في

العالم بالإضافة إلى أهميتها الاستراتيجية ووقوعها في مكان متميز عالمياً.

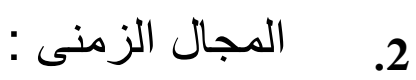

يتمثل في الفترة الزمنية التي تم بناء قصر شروان شاه فيها، والمراحل والاحداث التاريخية التي مرت عبر العصور المختلفة لهذا القصر ومدينة باكو، مما ساعد علي توضيح مكانة وأهمية القصر؛ والمدينة ومكانتها التاريخية والدينية قديماً سواء كان قبل الإسلام أو بعد الفتح الاسلامي، وكيف دخلت مرحلة جديدة من التقدم والحضارة في عصر دولة شروان شاه

$$
\text { أهم الصعوبات التي واجهت الباحث: }
$$

ندرة البيانات والمعلومات المتاحة ولذلك تم الاعتماد على المصادر والمراجع والرسائل العلمية الأجنبية التي قمت بترجمتها عن طريق مكاتب الترجمة المعتمدة.

$$
\text { أدو ات الدراسة : ت ت }
$$

استخدمت الدراسة الأدوات الأكاديمية العامة وهى الكتب العلمية من

$$
\text { (المصادر الأصلية - المراجع العربية والأجنبية - الدراسات والبحوث السابقة }
$$


تضمن البحث علي المقدمة ومجموعة من العناصر الرئيسية والخاتمة ثم الملاحق والصور ثم المصادر والمراجع، وجاء هيكل الدراسة

$$
\begin{aligned}
& \text { كالاتي : - n } \\
& \text { المقدمة } \\
& \text { أولاً: موقع مجمع قصر شروان شاه وسبب اختياره } \\
& \text { ثانياً: المنشئ وتاريخ الانشاء } \\
& \text { ثالثا: مادة البناء } \\
& \text { رابعاً : المراحل التاريخية للقصر } \\
& \text { خامساً : الاحداث التاريخية التي مرت بالقصر } \\
& \text { سادساً: تخطيط ومكونات مجمع قصر شروان شاه } \\
& \text { الخاتمة والتي تحتوي علي ( الملاحق والصور ، المصادر }
\end{aligned}
$$

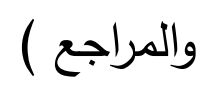




\section{قصر شروان شاه

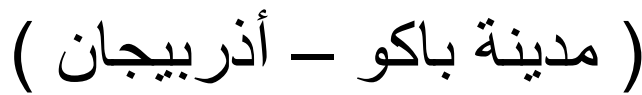

يعد قصر شروان شاه أحد القصور القليلة التي نجت حتى يومنا هذا من

الاندثار؛ وهو أحد المعالم الوطنية الاذربيجانية ومن الصعب العثور على عمل معماري في أذربيجان جذب انتباه العديد من المسافرين والباحثين مثل مُجَمَّع قصر شروان شاه بمدينة باكو بأذربيجان (4).

$\left.{ }^{4}\right)$ Kitabçası, Məlumat : AZəRBAYCANIN TARIXİ-MEMARLIQ ABIDӘLəRİ, Şərqiyyə, BAKI - 2008, c 99. 
حيث كان لهذا القصر دور كبير في الازدهار الحقيقي لدولة شروان شاه، والذي بلغ ذروته بالفعل تحت حكم شروان شاه خليل الله الأول ابن الثيخ ابراهيم، الذي حكم شروان من 821هـ/1417م إلى 869هـ / 1465م (5).

وسوف نتتاول بالدراسة والثرح والتحليل في الصفحات القادمة القصر الملكي لشروان شاه دراسة معمارية أثرية ، ولكن قبل ذلك سوف نتحدث عن الموقع والمنشى وتاريخ نشأة القصر ، ومادة البناء، والمراحل والأحداث التاريخية التي مرت بالقصر، وكذلك مكونات مجمع قصر شروان شاه .

\section{أو لاً: موقع مجمع قصر شروان شاه وسبب اختباره:}

تم بناء هذا القصر الرائع في الجزء القديم من مدينة باكو الحديثة بجمهورية

أذربيجان، والتي تعرف بالمدينة القديمة ( أشير شاهر Icheri Sheher) (6) ،

${ }^{5}$ ) Ширваншахов, Дворец : Баку, Издательский Дом "Şərq-Qərb ("EastWest"), 2013,c.8.

6) أثنير شاهر Icheri Sheher : المعروفه باسم "القلعة" أو ببساطة "الددينة القيمة" ، وتعد أثنير

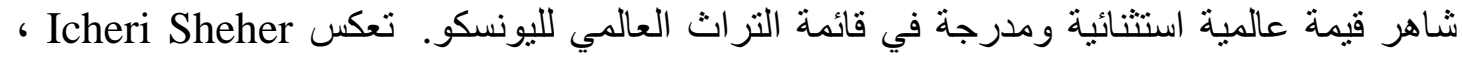

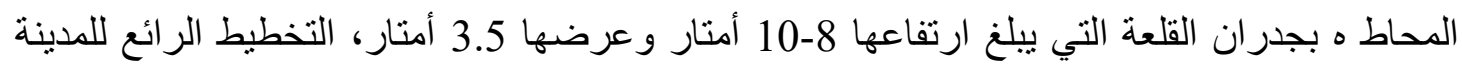

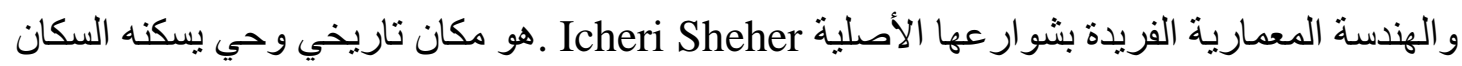

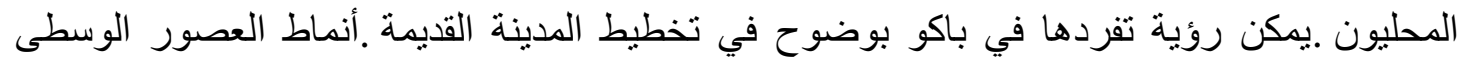

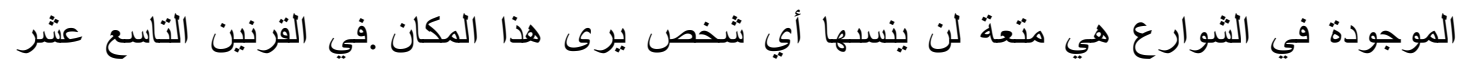

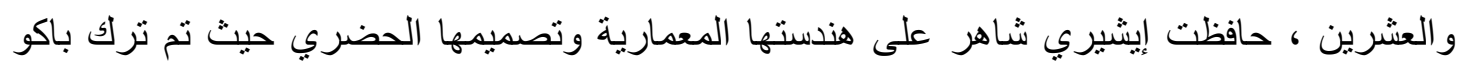

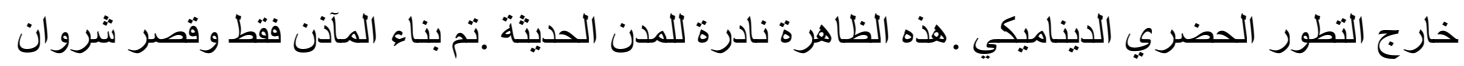

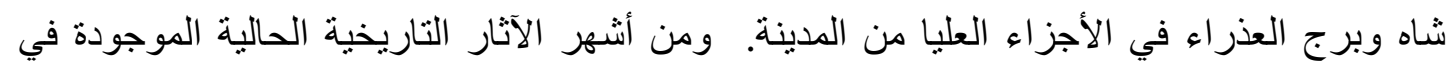
Icheri Sheher Mukhara Multani 
وتميز بين جميع المباني الأخرى بجماله وعظمته ، ومستوى البناء العالي والتعبير الفني الفريد، وقد تم هدم بعض أجزاء القصر في أوائل القرن التاسع عشر الميلادي وتم تكييفه لاحقًا لتلبية الاحتياجات العسكرية والاقتصادية للجيش الروسي(7). ويذهل مجمع القصر اليوم الزوار بالتتاغم والاكتمال المعماري الفريد من نوعه، وخاصة بعد أن تم إدراجه في قائمة التراث العالمي لليونسكو بعد أن تم ترميمه وفقاً للمعايير الدولية الحديثة، وكذلك إعلان مجمع قصر شروان شاه من قبل الدولة "محمية معمارية تاريخية ومتحف مفتوح؛ يتيح الفرصة للانغماس في أجواء العصور الوسطى (8). أما عن سبب اختيار موقع القصر، وسبب إنثاءه، ورد في ذلك أن الثيخ إبراهيم قد صعد في يوم ما على تلة في أعلى نقطة في مدينة باكو وقال: "من هنا تكون المدينة بأكملها مرئية في لمحة" ، وفي هذه اللحظة مر بخاطر الثيخ إبراهيم ذكرى بناء مدينة شروان شاه، وحرفيا يعنى تلك المدينة التاريخية لأذربيجان الثمالية ، المتاخمة للتلال غربا وبحر قزوين شرقا والتي تضرب بجذورها العميقة للعصر

المعمارية الأخرى، وجميعها تعبر عن الثقافة الإنسانية بأصالتها وجمالها الفريد في هذه الحقب التاريخية الهامة من تاريخ المدينة. الموقع الرسمي للقصر.

https://icherisheher.gov.az/az/93-sirvansahlar-saray-kompleksi/

$\left.{ }^{7}\right)$ Kitabçası, Məlumat : AZORBAYCANIN TARIXİ-MEMARLIQ ABİDLLӘRI, Şərqiyyə, BAKI - 2008, p.100.

$\left.{ }^{8}\right)$ Рахманова, Лейла : Музеи, заповедники, галереи Баку, Издательский Дом "Golden Book", baku, 2015, s.66. 
الساساني(9) (القرنان الثالث والسابع الميلادي) حتى ذلك الحين ، حيث اتقق الثاه خسرو(10) مع القبيلة المحلية السائدة في هذه الأجزاء بالاسم العرفي شروان (شارفان) لحماية الممرات الجبلية للقوقاز بشكل مشترك من القبائل البدوية الثمالية التي تأتى لنهب المنطقة. مرورا بالفتح العربي في عهد الخليفة الثاني - عمر بن الخطاب رضى الله عنه (13هـ/634-23هـ/644م) ، الذي نشر الإسلام في نطاق القوقاز (11). ومثل خسرو ، عهد الخليفة بحماية المنطقة إلى زعيم هذه المنطقة ، والذي يسمى الآن شروان شاه وبموجب الاتفاقية ، كان على شروان شاه حماية الحدود الثمالية للعالم الإسلامي من غارات البدو الرحل، ومن هنا قرر الثيخ إبراهيم

9) العصر الساساني : الساسانيون هم أخر أسرة حكمت ايران قبل دخول الاسلام، وامتد حُكم الدولة الساسانية في إيران لفترة طويلة خلال الفترة (226-651م)، وبالإضافة إلى إيران حكَّ النَّاسانيون أجزاء كبيرة من العراق، حيث نجح بابك بن ساسان عام 226م في توحيد إيران بإنشاء مملكة إيلان (المسّاسان) التي كانت عاصمتها طيسفون Ctesiphon التي يُسيها العرب [الدائن] في بلاد الرافدين،

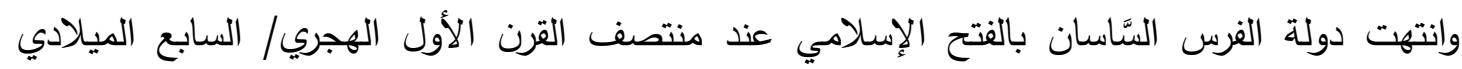

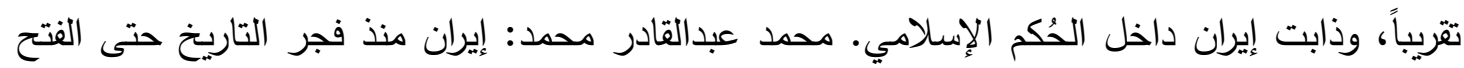

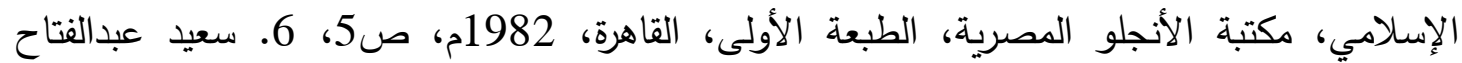

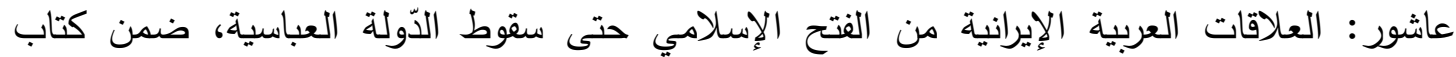

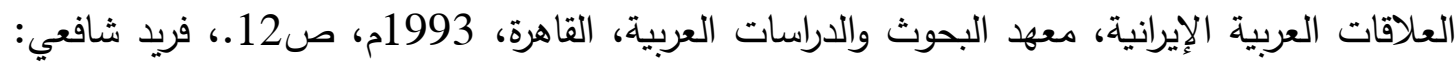

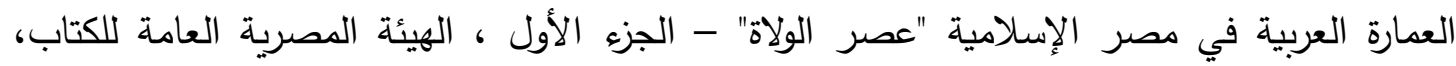

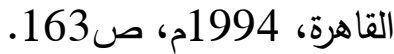

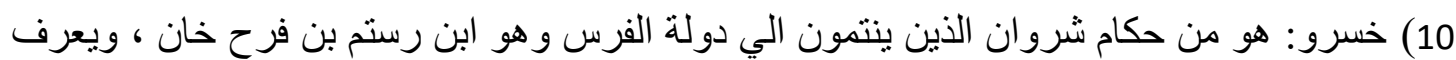

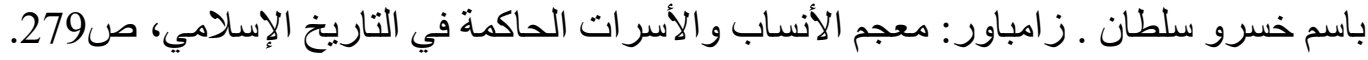
11 11 ) عرف الجغرافيون و المؤرخون المسلمون القدامى أرض القوقاز وخاصة الجزء الجنوبي منه، بأسم بلاد

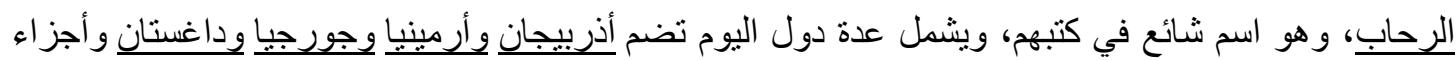

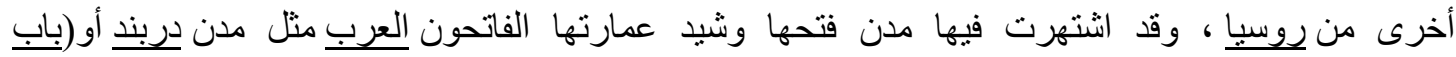

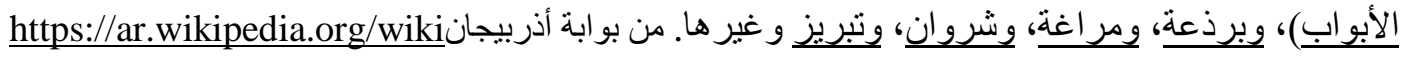


بناء قصر شروان شاه للسكن والدفاع عن الددينة بأكملها، في هذا الموقع

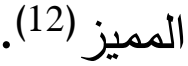

ثانياً: المنشئ وتاريخ الانشـاء ( خليل الله الأول بن الثيخ ابر اهيم(821-821هـ) (13):

ينسب تأسيس هذا القصر الي الثيخ إبراهيم بن محمد دربند بن كيقباد (784هـ/ 1382م-821هـ/1467م) (14) الذي شرع في بناء قصر شروان شاه ، وقد أُثبت اسم المنشئ علي نقش مثبت على أحد جدران الحصن في سكن سلالة

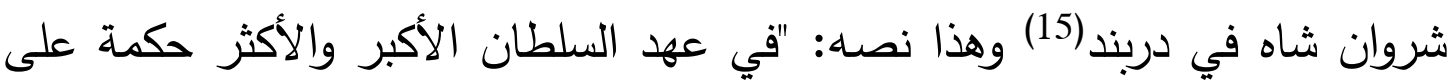
الثعوب ، السلطان الثيخ إبراهيم بارك الله فيه ووسع ممتلكاته تم إنثاء هذا الحصن"؛ ثم تعرض القصر لسلسلة من التجديدات والاضافات علي يد خّليفة الثيخ إبراهيم ونجله الثروان شاه خليل الله الأول (821هـ/ 1417م-869هـ/1465هـ)

$\left.{ }^{12}\right)$ Ширваншахов, Дворец : Баку, Издательский Дом "Şərq-Qərb ("EastWest"), 2013,c.9.

13 ) ز امباور: معجم الأنساب والأسرات الحاكمة في التاريخ الإسلامي، أخرجه زكي محمد حسن، حسن

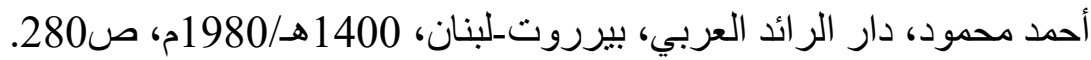
14 ) زامباور : معجم الأنساب و الأسر ات الحاكمة في التاريخ الإسلامي، ص280. 15 ) دربند: باب الأبواب على بحر طبرستان وهو بحر الخزر وهي مدينة أكبر من أردبيل نحو ميلين في ميلين

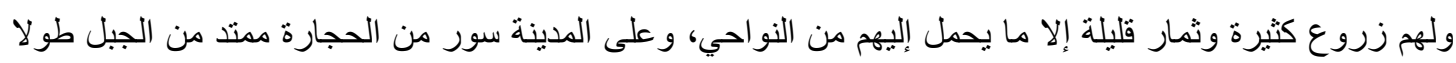

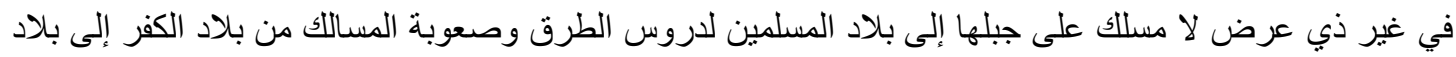

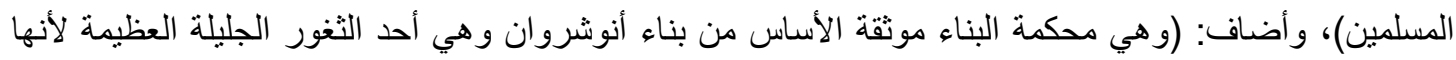

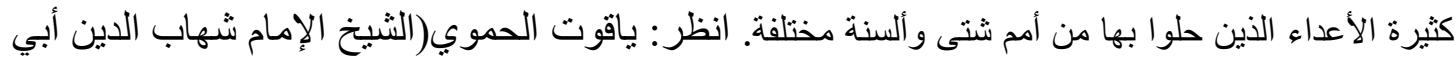

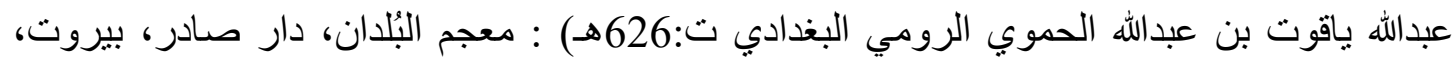


الذي ازدهرت البلاد خلال فترة حكمه التي امتدت لنحو خمسين سنة(16)، واتسع نطاق البناء في شروان(17) وباكو(18) وخاصة في مقر قصر العاصمة( قصر شروان شاه )، وأخذ أبعاداً غير مسبوقة بإضافة العديد من المباني للقصر، تثتمل معظمها علي نقوش ثبت إنشائها في عهد الشروان شاه خليل الله الأول ومنها نقش علي البوابة الرئيسية للقصر وجاء نصد: "في عهد أكثر الأسياد تبجيلًا ، الأشرف والأكرم والأعدل(19) الشروان شاه خليل الله الاول تم بناء هذا المبني "، والشاه خليل الله الاول منشئ هذا القصر الذي حكم في الفترة (821هـ/ 1417م866هـ/465ـ) كان أكثر أفراد قبيلة شروان جدارة وإنصافًا، ويمثل عهده ذروة 16) FəRHADOĞLU, Kamil : BAKI. İÇəRIŞ̧HӘR. BAKI,2006, s.100.

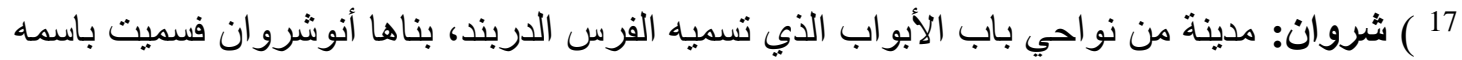

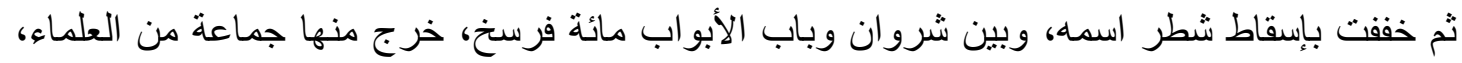

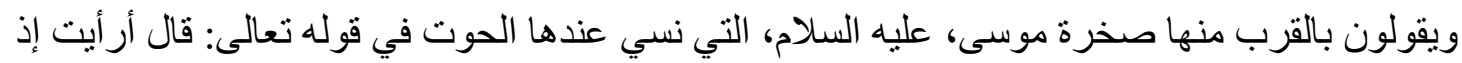

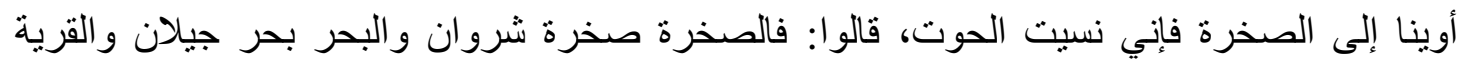

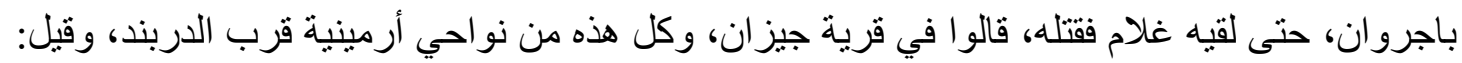

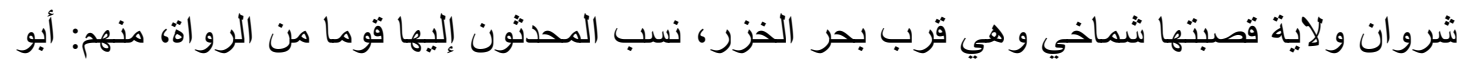

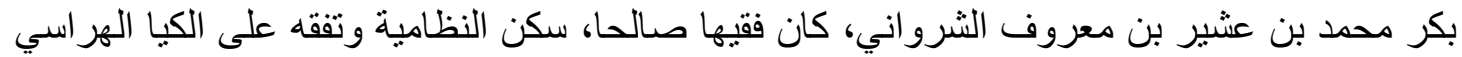

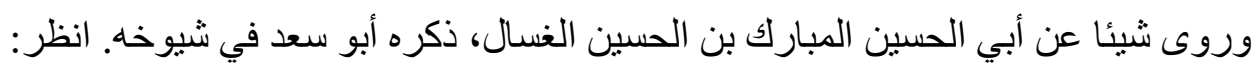

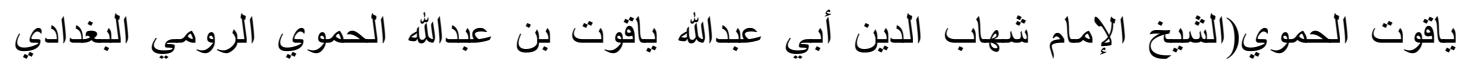

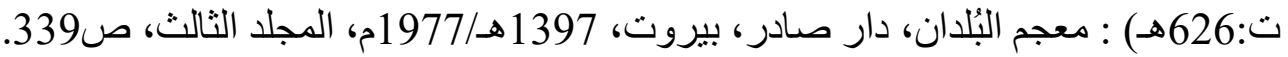
18) باكويه: بضم الكاف، وسكون الواو، وياء مفتوحة بلد من نواحي الدربند من نواحي الثروان فيه فيه

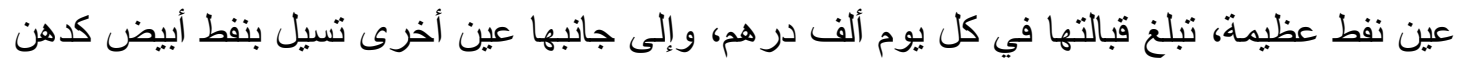

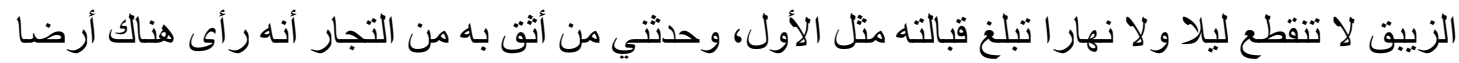

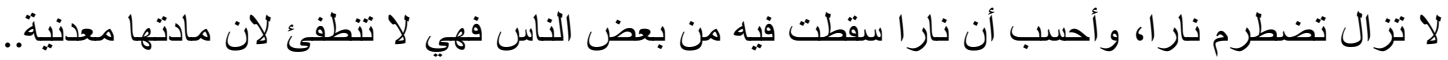

ياقوت الحموي: معجم البُّلان، بيروت، المجلد الأول، ص328.

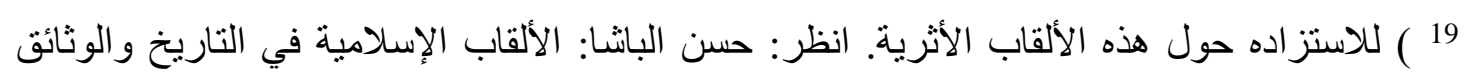

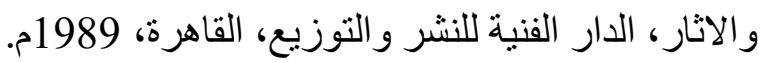


الدولة والثقافة الحضارية بحرفها وحياتها الروحية والعلمية، وكذلك مثل والده في سياسته الخارجية ، التزم بالتوجه والتعامل مع التيمورين(20).

ومن أجل توطيد العلاقات مع ملوك التيموريين ميران شاه(21) و شاه رخ(22) ، الذي كان على خليل الله أن يقوي علاقاته معهم من أجل الحفاظ على استقلالية شروان. وانطلاقا من هذا المنظور وفي بداية القرن التاسع الهجري / الخامس عشر الميلادي ، غير شروان شاه لقبهم الناطق باللغة الفارسية شاه إلى لقب باللغة التركية الجديدة، وعلي الرغم من ذلك لم يرتبط هذا اللقب طويلاً بعائلة ودولة شروان لدرجة أننا لم نستطيع معرفته، والثابت لدينا هو ان الحاكم في دولة شروان كان يلقب بلقب شروان شاه(23).

ولم يكن خليل الله الأول أقل من والده في البصيرة واتساع الآراء والقدرات الدبلوماسية ، فقد أرسل من شروان في عام 824هـ/1420م هدايا قيمه إلى شاه رخ حيث أهدي الي شاه رخ حزام ثمين؛ ومن هنا تعززت صداقة الزعيمين، وبناء على طلب شاه رخ بتعزيز العلاقات الأسرية تمت خطبة خليل الله الاول علي حفيدة $\left.{ }^{20}\right)$ Ширваншахов, Дворец : Баку, Издательский Дом “Şərq-Qərb ("EastWest")2013,c.25.

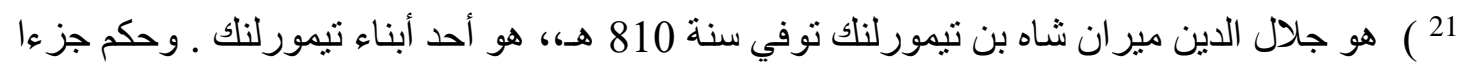

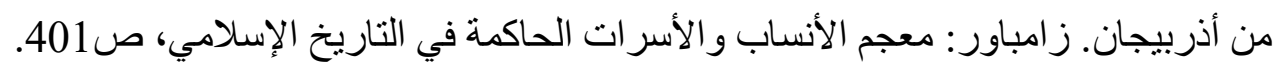

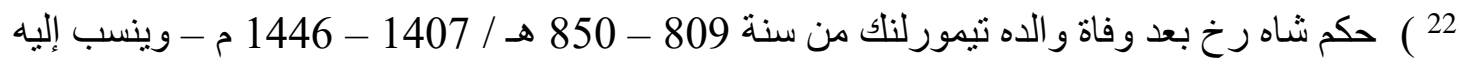

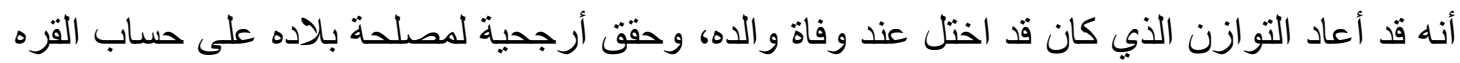

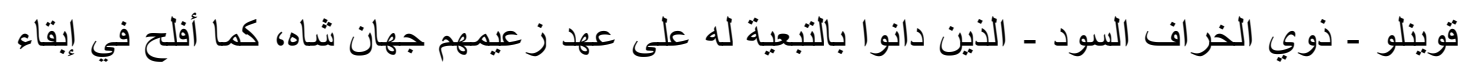

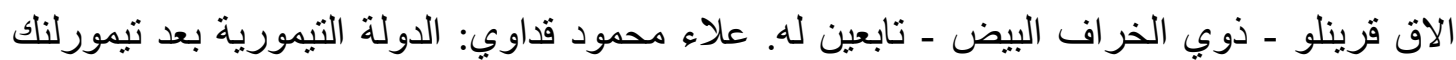

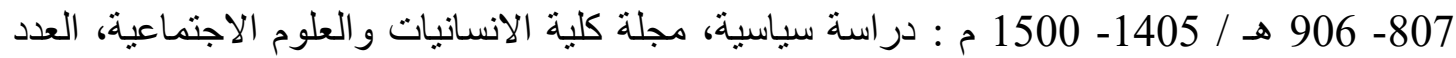

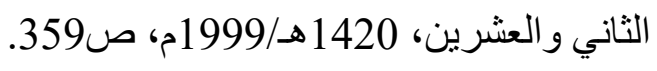

23) Ширваншахов, Дворец : Баку, Издательский Дом,с.26. 
ميران شاه والتي كانت تسمي هانكي، وفي هذه المناسبة وصلت والدة خليل الله الاول بيكى خاتون بهدايا قيمة، وفي عام 825هـ والموافق 3 أبريل 1421م ، أقيم حفل زفاف رائع في كاراباخ(24)، مما عزز اتحاد شروان شاه مع التيمورين عن طريق هذا الزواج؛ وهذا كان سبب في حماية أسرة شروان شاه من الاستيلاء والدمار والحروب

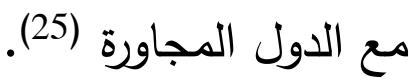
وبعد ذلك قرر خليل الله الاول أن يقوم بعدد من الأعمال الخيرية يتولى إدارتها بنفسه، وقام بتطوير بناء واسع النطاق في جميع أنحاء شروان حيث قام بترميم الأضرحة الإسلامية ، وتخصيص أراضي الأوقاف ، وآبار النفط ومناجم الملح لتدر ريعاً يصرف منه علي مصالح المساجد وأرباب الوظائف، كما تم إنشاء عدد كبير من الخانات( كرفان سراي ) التي تم بناؤها على حساب الدولة لضمان تجارة الترانزيت دون انقطاع، والتي جلبت عائدات ضخمة للخزانة. وكذلك قام ببناء وترميم قلاع الدفاع والقوافل والجسور (26) في باكو وشَمَاخِي(27) و دربند ، وارتبط إنثاء هذا القصر بظروف اقتصادية وسياسية واجتماعية معينة استجدت في عهد

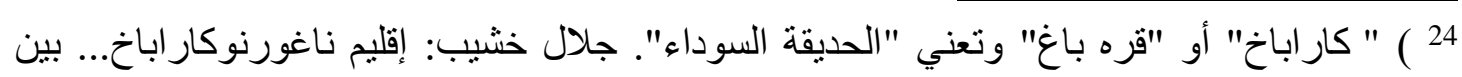

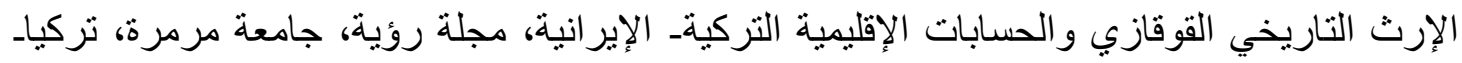

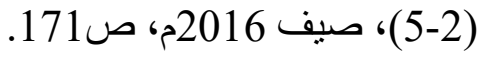

$\left.{ }^{25}\right)$ Ширваншахов, Дворец : Баку, Издательский Дом,с.27.

$\left.{ }^{26}\right)$ FORHADOĞLU, Kamil : BAKI. İÇəRIŞ̧HӘR.2006, BAKI, s.101.

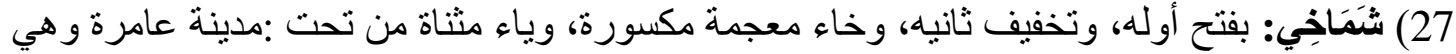

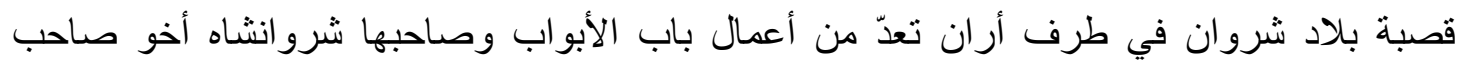

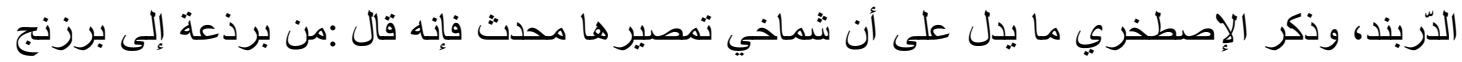

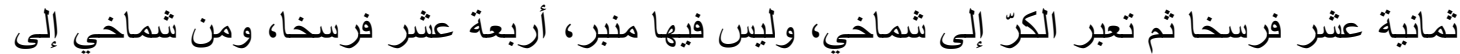

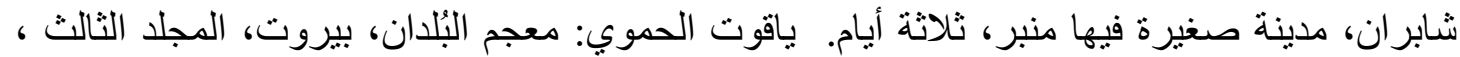


خليل الله الأول نتيجة ازدهار التجارة غير المسبوقة مع الدول الأوروبية من خلال المواد الخام الاستراتيجية مثل النفط والحرير والملح والزعغران ، ومن خلال التجار الفينيسيين(28) الذين أسسوا مراكزهم التجارية في باكو وتصدير البضائع عن طريق بحر قزوين و من هناك إلى أوروبا(29). وترتب علي ازدهار التجارة تدفق أمواج من التجار الأوروبيين لشروان في النصف الثاني من القرن التاسع الهجري / الخامس عشر الميلادي ، بعد أن دخل الأتراك - العثمانيون القسطنطينية عام 457هـ/1533م، تم تحويل طرق التجارة العالمية من البحر الأسود إلى بحر قزوين وكان هذا نتيجة للسياسات الأوروبية التي تهدف إلى إضعاف تركيا العثمانية ، والتي شكلت خطرًا متزايدًا على أوروبا، وبالنظر إلى كل هذا وفر خليل الله الاول جميع الظروف المناسبة للتجارة والتصدير والعبور من جنوب شرق آسيا (الهند ، الصين) عبر بحر قزوين ، ونتيجة لذلك تم إثراء خزانة شروان في وقت قصير لدرجة أنه كان من المكن تتفيذ أكثر الخطط جرأة لتحسين البلاد وتحديثها؛ ونتيجة لعبور البضائع محلياً ودولياً إلى جانب التجارة ، جاء الدخل الضخم وعدد كبير من الحرفيين الذين شكلوا أحياء بأكملها في الدينة، ومن هنا ازدهر إنتاج الأطباق الخزفية والسجاد والأشغال المعنية والأسلحة التي تعرض حاليا في متحف قصر شروان شاه، وكذلك ازدهرت حرف البناء في جميع مدن شروان (30).

28 ن نسبة إلى فينيسيا بايطاليا.

$\left.{ }^{29}\right)$ Ширваншахов, Дворец : Баку, Издательский Дом ,с.29.

30) Лейла Рахманов : Музеи, заповедники, галереи Баку (пособие для туристов) , Баку ,2015 , С 65 
وقد تثكلت في المدينة ، وبإدارتها الإدارية المتميزة، شبكة من المؤسسات التعليمية (المدارس) ، التي علمت الفلسفة والثريعة الاسلامية ، فكانت بحاجة إلى مباني جديدة. حيث لم يعد بإمكان عدد كبير من خدمات المدينة الجديدة العمل في المدينة لضعف البنية التحتية ، ومن هنا تم خلق الظروف المناسبة، وظهرت الحاجة إلى بناء مدينة حضرية مع بنية تحتية متطورة ، فانطلقت اكبر حركة عمرانية في المدينة في تلك الفترة الزمنية(31).

ومن هنا قرر خليل الله الاول البدء في تتفيذ أكثر مشاريعه طموحاً ، الذي خلد اسمه وهو قصر شروان شاه ، الذي كان والده قد شرع في بناءه، كذلك قام شروان شاه خليل الله ببناء جميع الأراضي من حوله لتصبح مجمعًا للقصر الملكي حقًا ، مع إضافة مسجد(32) جديد وقبر وحمام القصر ومكتبة وحديقة ومباني أخرى، وللعمل في هذا المشروع ، تم جمع أفضل المهندسين المعماريين والمهندين الفنيين والبنائين والنحاتين والخطاطين من جميع أنحاء شروان، ومن بينهم مهندسون مثل حاج أحمد من دربند وتاج الدين وغيرهم من أبرز الحرفيين(33).

1)Искендер Тагиев: Дворец Ширваншахов или Ханака С.Я.Бакув, ÇAŞIOĞLU ,Баку ,2003,С8 . Ширваншахов, Дворец : Баку, Издательский Дом ,с.32.

32 ) المسجد : هو مكان الصلاة عند المسلمين ويعرف بمسجد الخمسة إذا لصلاة الخمسة فروض فقط، فاذا وضع فيه منبر وأقيمت فيه صلاة الجمعة سمي المسجد الجامع، فاذا كانت به خلاوي للصلوات سمي بالمسجد الجامع الخانقاة ـ سامي محمد نوار : الكامل في مصطلحات العمارة الإسلامية من بطون المعاجم اللغوية، دار الوفاء، القاهرة، 2002م، ص167.

33) Ширваншахов, Дворец : Баку, Издательский Дом ,с.33. 
تم بناء جميع المباني المكوّنة لهجمع القصر من الحجر الجيري(34 الدحفور في أبشيرون(35)، والذي يُطلق عليه مسىى "حجر أبشيرون المحلي" ذي اللون الأصفر؛ وجدير بالذكر أنه قد شارك أفضل النحاتين في فن الحجر والخشب والجص، وكذا الفنانين في رسم العناصر الزخرفية للقصر، على جميع أنواعها ؛ سواء كانت زخارف نباتية وهندية منحوتة، غطت الجدران والعقود وفتحات الأبواب والنوافذ، لتثكيل شبكات معقدة من الزخارف الفنية الرائعة، وتتميز الخزائن الحجرية الملصقة في القاعات والغرف بديكور مزين بالفنيفساء ، مما يذهل الخيال بثروات

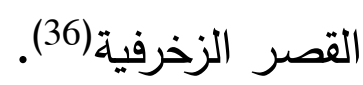

وجدير بالذكر أنه عند اطلاعي على أحد المراجع الهامة باللغة الأذربيجانية، لدراسة هذا القصر، في ترجمتي له فيما يتعلق بالحديث عن مادة البناء، ذكر ما

${ }^{34}$ ) Kitabçası, Məlumat : AZORBAYCANIN TARIXİ-MEMARLIQ ABIDӘLӘRI, Şərqiyyə, BAKI - 2008, p.100.

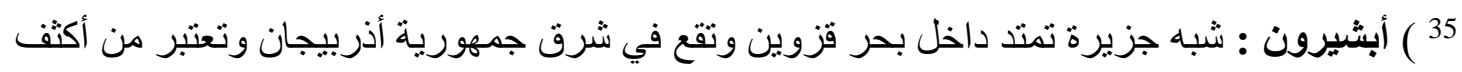

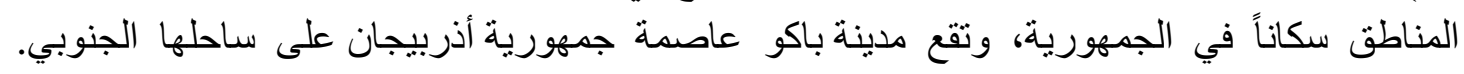

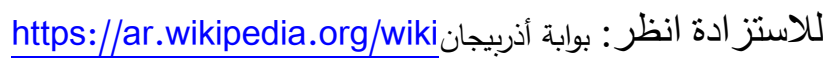

$\left.{ }^{36}\right)$ Ширваншахов, Дворец : Баку, Издательский Дом ,с19. 
نصه : " تم بناء جميع مباني المجمع من حجر اللوز المحلي ، وهو الحجر

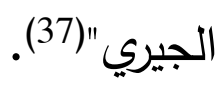

مما يُضيف إلى معلوماتتا أن هذا المصطلح المعماري والمتعلق بالبناء "حجر

اللوز الجيري"، يعد أحد المصطلحات الأثرية الدارجة في هذا القطر .

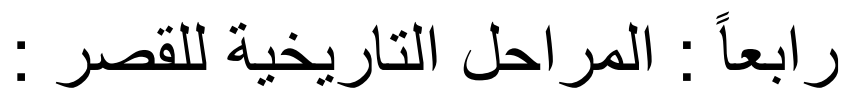

بعد تدمير شماخي بواسطة زلزال مدمر في عام 587هـ/ 1191م ، جعل شروان شاه (أكستان(38)) مدينة باكو، التي أصبحت العاصمة الثانية لشروان مقراً لإقامته، وعلى الارجح أنه عاش فيها حتي نهاية القرن الثاني عشر الميلادي، واهتم بالدفاع عن المدينة كما يتضح من النقوش في نهاية القرن الثاني عشر الميلادي الموجودة علي بعض مباني القصر ؛ حيث يوجد العديد من الهياكل الدفاعية والأبراج والقلاع والجدران والمباني السكنية ، سواء في المدينة أو في أبشيرون ، ومن هنا يمكننا أن نفترض أن نقل عاصمة شروان من شماخي إلى باكو تم في عام 587هـ 1191م • ومن ثم في عهد خليل الله الاول الذي كان يعمل علي تحسين بلاده وعاصمة دولته باكو ، بدأ بناء مجموعة قصر شروان شاه والقوافل والجسور. وازدهرت البلاد خلال حكم شروان شاه خليل الله الاول لنحو خمسين سنة الذي توفي في شهر ذو الحجة 869هـ- 1465م (39).

$\left.{ }^{37}\right)$ FəRHADOĞLU, Kamil : BAKI. İÇəRIŞəHӘR. BAKI, "Ş-Q" \& "ÇİNAR-ÇAP", 2006, s.115.

1)(أكستان : الثروان شاه أكستان الاول بن منوجهر حكم من عام 556 هـ حتي عام 566 هـ ،

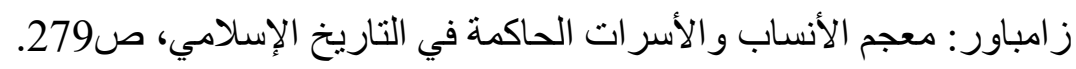

2) Азернешр, История Баку сквозь века. Султанова БАКУ,1992,с100. 
ومن هنا كان القرن الخامس عشر الميلادي فترة إحياء اقتصادي وثقافي لشروان؛ حيث أن هذه الفترة كانت فترة سلام وهدوء لدولة شروان ومن ثم كان هناك تقدم كبير في الفن والهندسة المعمارية والتجارة وغيرها من الانثطة(40).

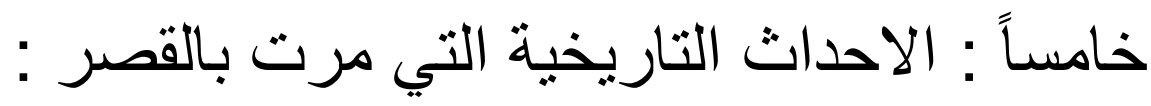

بعد مقتل شروان شاه فاروق يسار (41) ابن خليل الله الاول خلال المعركة التي وقعت بينه وبين الصفوين في عام905هـ/1500م ، استولى الصفويون على باكو وتم نهب القصر، ومن غير المعروف من الذين عاشوا في القصر بعد شروان شاه فاروق يسار خلال هذه الفترة(42).

كما وقعت في أذربيجان حروب لا نهاية لها على السلطة في جنوب القوقاز بين إيران وتركيا، وتعرضت شروان الواقعة عند مفترق طرق القوافل التجارية للهجوم بثكل متكرر وتم الاستيلاء على القصر خلال هذه الهجمات، ويتضح ذلك من

40) Bünyadov T.A. Azərbaycan arxeologiyası oçerkləri. Bakı, Azəməşr, 1960,s 216 .

41) هو ابن خليل الله الاول الذي أتم بناء قصر شروان شاه بعد أبيه الثروان شاه الثيخ ابراهيم ، وحكم فاروق يسار ( فُرْخ يسار ) من عام 869 هـ حتي عام 906 هـ ـ زامباور : معجم الأنساب والاسرات الحاكمة في التاريخ الاسلامي ، ص281.

42) FӘRHADOĞLU, Kamil : BAKI. İÇəRIŞəHӘR. BAKI, "ÇİNAR-ÇAP", 2006, s.117. 
خلال بوابة مراد الشرقية والتي بُنيت خلال حكم الأتراك، والتي قام ببنائها السلطان مراد الثالث (43) كمدخل للقصر .

وفي عام1135هـ/1723م ، عندما فتحت قوات بيتر الأول النار على باكو تضررت الواجهة الثمالية الثرقية لمسجد القصر وكتب عن ذلك الدكتور (ب. كوك) ، الذي كان في باكو عام1160هـ/1747م حيث قال : "يوجد قصر غني في هذه المدينة ، مبني من الحجر الصلب، وجدنا أثار التدمير به تعود الي عام1135هـ/1723م حيث دمرته القذائف الروسية"(44). وبعد احتلال روسيا لأذربيجان في عام 1243هـ الموافق 10 فبراير 1828م وتحويل مباني القصر إلى المقر العسكري الروسي ، تم تنفيذ أعمال الإصلاح في مباني قصر شروان شاه ، وكذلك تم الاستغناء عن بعض المباني القيمة المتبطة

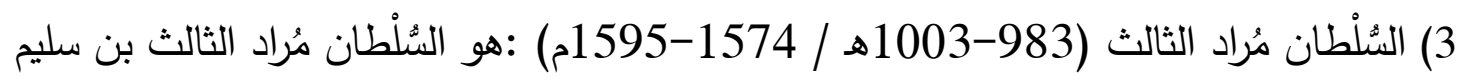

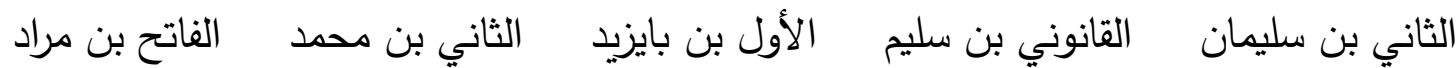

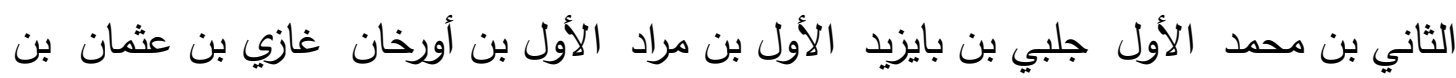

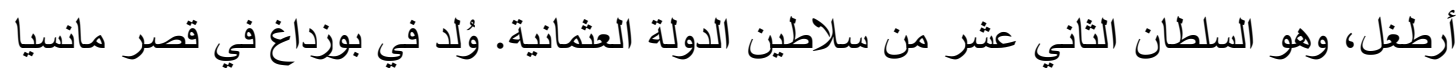

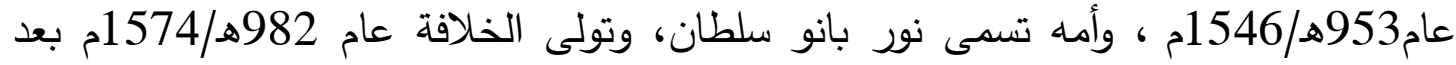

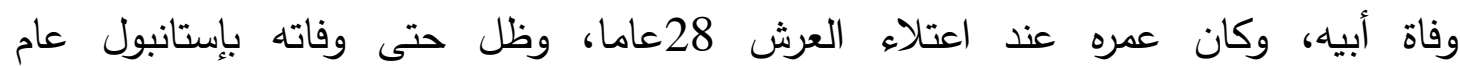

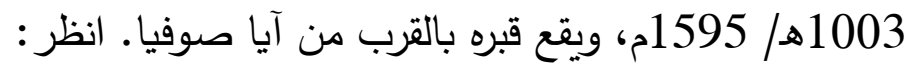

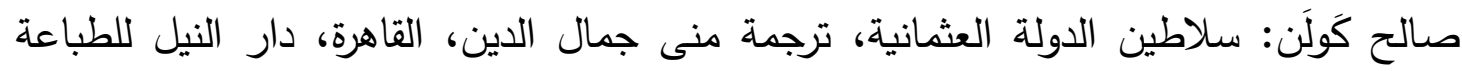

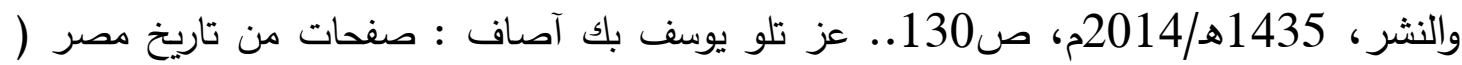

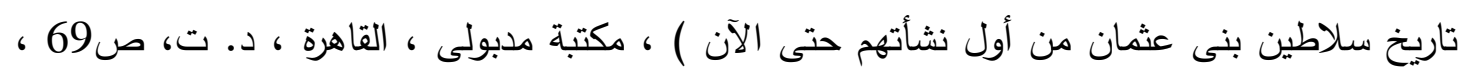
.70

44) Левиатов В: Археологические раскопки 1945 года при Ширваншахов в городе Баку. Изв.АН Азерб.ССР1948, № 1, с.115. 
بالقصر • حتى أنه تم التخطيط لبناء كنيسة ألكسندر نيفسكي على أراضي

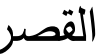

وتم تدمير القصر وإهماله في نهاية القرن التاسع عشر، ولكن في عام 1336هـ الموافق 5 أكتوبر عام 1918م، نُشر مرسوم جمهورية أذربيجان الديمقراطية "بثأن جرد وحفظ الآثار والمعالم الأثرية العائدة للمجتمع والمؤسسات والأفراد"، وكان هذا مرسومًا بشأن أول تسجيل للآثار من قبل الدولة وتم تسجيل قصر شروان شاه لؤلؤة العمارة الاذربيجانية باعتباره أهم المعالم المعمارية الأثرية ليس في أذربيجان فقط ولكن علي مستوي العالم(46). وفي عام1351هـ/1932 م ، على أساس قرار جمهورية أذببجان الاشتراكية السوفيتية ، بدأت أعمال الإصلاح في مجمع شروان شاه.

وفي عامي1356هـ/1937 و1357هـ/1938م تم تتفيذ الأعمال الأثرية في القصر تحت قيادة عالم الآثار VN Leviatov. وخلال الأعمال الأثرية والحفريات تم العثور على مواد من القرنين الثاني عشر إلى الخامس عشر الميلادي في القصر، وكذلك أثناء تتظيف الآبار في فناء القصر ، تم العثور على كسرات من الأواني الخزفية في اثنتين منها، والتي كانت ذات قيمة عالية، وتتثابه أنماط أواني الفخار داخل الاكتشافات مع أنماط أطباق البورسلين • وتم العثور أيضا على

45) Левиатов B: Археологические раскопки , С 117 . FəRHADOĞLU, Kamil : BAKI. içəRIŞəHəR. BAKI, "ÇINAR-ÇAP", 2006, s.119.

46) FəRHADOĞLU, Kamil : BAKI. İ̧̧RişəHəR. BAKI, "ÇINAR-ÇAP", 2006, s.119. 
المصابيح الملكية المحفوظة الان في متحف التاريخ الأذربيجاني في الفناء الأوسط(47).

وفي عام1373هـ/1954م ، تم تحويل "مجمع قصر شروان شاه" إلى المتحف التاريخي والمعماري للدولة؛ وفي عام1379هـ/1960م، وقررت الحكومة الجمهورية حماية القصر واعتباره نصب معماري تاريخي تذكاري يعبر عن أطول دولة عاشت في دولة أذربيجان وهي دولة شروان شاه (48).

ثم في عام1383هـ/1964م تم تسمية مجمع قصر شيروان شاه، بمتحف الدولة التاريخية(49).

Icheri ) ومن أجل الحفاظ على المعالم المعمارية في المدينة القديمة Sheher )، ووفقا لقرار مجلس وزراء أذربيجان عام 1396هـ بتاريخ 10 أغسطس عام 1977م، تم إعلانها محمية للآثار المعمارية التاريخية والتي من بين كنوزها قصر شروان شاه(50).

وفي عام1421هـ/2000م أدرجت اليونسكو مجمع قصر شروان شاه في قائمة التراث العالمي ، ومنذ ذلك الوقت حتي يومنا هذا والقصر يعتبر متحف

47) Левиатов В.Н. Археологические раскопки 1945 года при Ширваншахов в городе Баку. Изв.АН Азерб.ССР, № 1, 1948, № 1, с.17.

${ }^{48}$ ) FӘRHADOĞLU, Kamil : BAKI. İÇəRIŞ̧HӘR. BAKI, s.116.

49 ) deyerlerimiz.az (in Russian). Retrieved 6 June 2018.

50) FӘRHADOĞLU, Kamil : BAKI. İÇəRIŞ̧HӘR. BAKI, s.116. 
تاريخي معماري مفتوح يعبر عن عظمة الحضارة الاسلامية الأذربيجانية يجذب إليه ملايين السائحين كل عام(51).

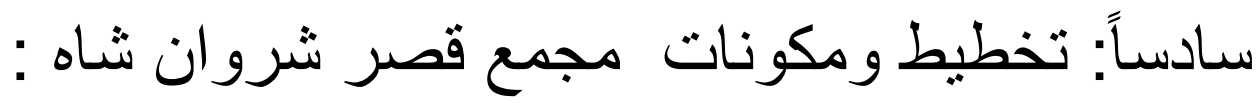

في عهد خليل الله الأول (1417-1462م) أُقيم قصر شروان شاه في أعلى

نقطة في المدينة ، ويتكون مجمع القصر (لوحتا6،5 ) من: القصر الملكي، الديوان

51) https://icherisheher.gov.az/az/93-sirvansahlar-saray-kompleksi/ 
خانة ، ضريح السيد يحيي الباكوفي، مسجد كيقباد، بوابة مراد الشرقية، ضريح عائلة شروان شاه، مسجد شروان شاه، وحمام القصر ، وخزان المياه(52.

ويقع هذا القصر الذي يعتبر أحد المباني المعمارية المتميزة في ثلاثة مستويات ، والتي تختلف عن بعضها البعض على ارتفاع 5.6 متر ، ولم يتم بناء القصر وفقا لخطة معمارية واحدة، وعلى الرغم من ذلك لا يتعارض أحد المباني مع الآخر ؛ بل علي العكس من ذلك تجد أحدهما يقوم بتجميل الآخر، وقد تم بناء جميع مباني المجع من حجر اللوز المحلي ، وهو الحجر الجيري(53). وتتصل جميع هذه المباني ببعضها البعض عن طريق السلالم الحجرية، وتحدها الجدران والأبواب، يقع في الفناء العلوي مبنى القصر والديوان خانة، ضريح السيد يحيى باكوفي، وبوابة مراد الثرقية ، وفي الفناء الثاني أو الأوسط يقع مبنى ضريح أسرة شروان شاه والمسجد، وأخيراً في الجزء السفلي يقع مبنى الحمام وخزان المياه. ومن خلال الحفريات الأثرية في موقع القصر ، تم تحديد أن مباني وهياكل القصر لم يتم بناؤها في نفس الوقت ولكن في أوقات تاريخية مختلفة ، وكان أولها بالطبع بناء القصر الملكي (54).

1) Ахундов Д. А , Архитектура древнего и раннесредневекового Азербайджана , ,Баку, Азернешр, 1986, С 56.

53) FəRHADOĞLU, Kamil : BAKI. içəRiş̧НHR. BAKI, "ÇINAR-ÇAP", 2006, s.116.

${ }^{54)}$ Kitabçası, Məlumat : AZӘRBAYCANIN TARIXİ-MEMARLIQ ABIDӘLӘRİ, p.99. 
وفي الرسم التوضيحي التالي يتضح لنا تخطيط ومكونات قصر

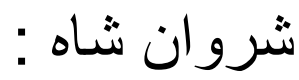

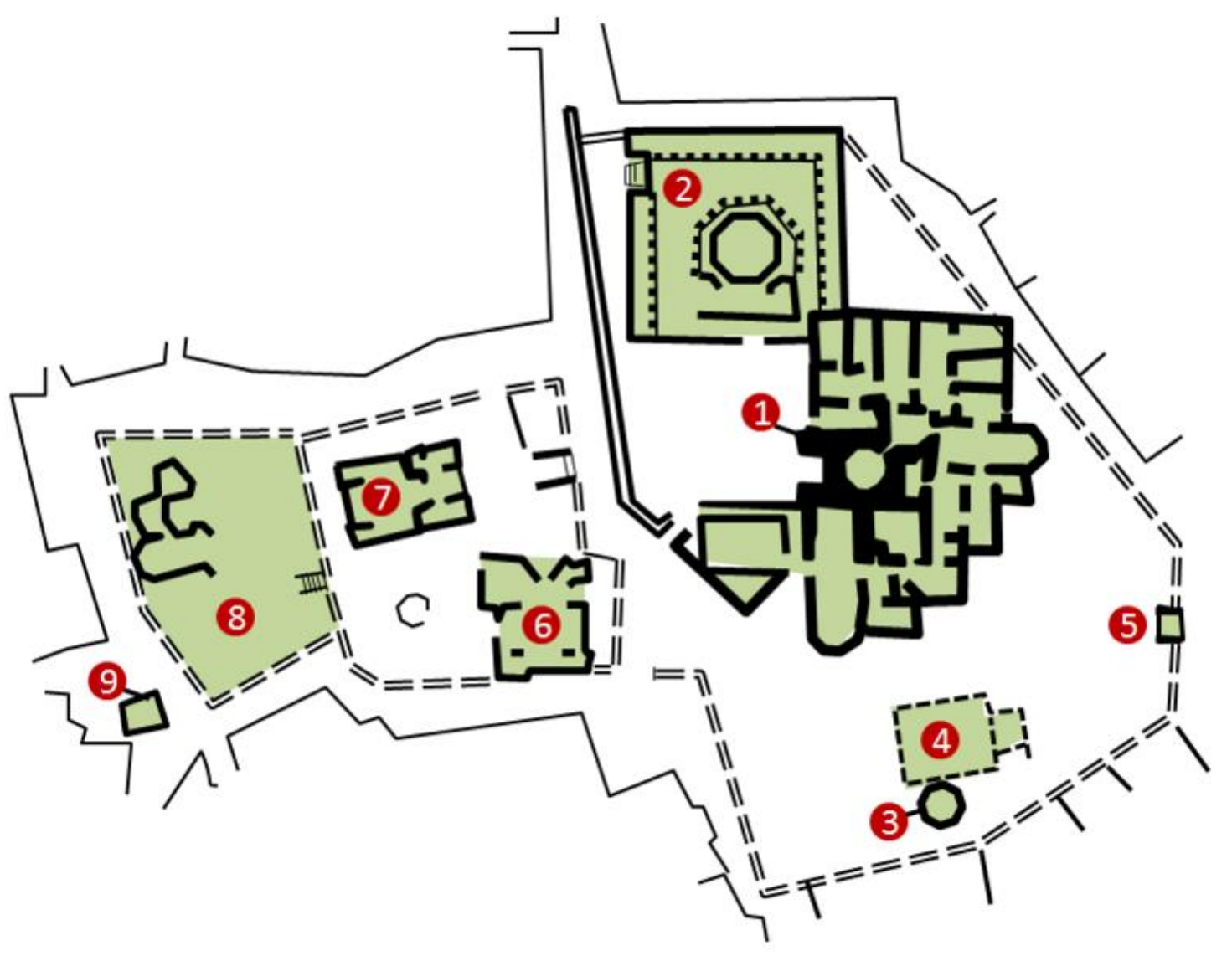

$$
\begin{aligned}
& \text { 1. القصر المكي ( قصر شروان شاه ) . } \\
& \text { 2. الديوان خانة . } \\
& \text { 3. ريح السيد يحيي الباكوفي . } \\
& \text { 4. مسجد كيقباد . } \\
& \text { 5. بوابة مراد الثرقية. } \\
& \text { 6. مسجد القصر . }
\end{aligned}
$$

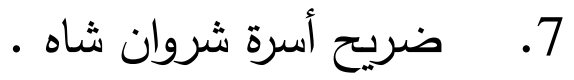

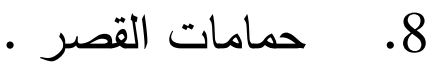




$$
\text { 9. الصهريج ( خزان المياه ) . }
$$

\section{مبنى القصر ( قصر الحاكم شروان شاه ) (لوحتا 7،8):}

القصر عبارة عن مبنى مكون من طابقين في شكل مستطيل غير منتظم، وتم تمهيد الزاوية الجنوبية الثرقية من المبنى المواجه للفناء السفلي لإعطاء إضاءة جيدة للقصر (55). حيث تم بناء القصر الذي كان يسكنه شروان شاه في هيكل معماري متميز على صخرة في أعلي نقطة تعلو المدينة القديمة في باكو (56)، الجانب الرئيسي من المبنى يواجه الفناء العلوي للمجمع، وجاء تصميمه بسيط ورائع(57). ويعتبر هذا القصر بمثابة مدينة من الداخل حيث يوجد به العديد من الغرف والممرات والمخازن والجداران السميكة التي تم تطعيمها بالزخارف الإسلامية أثناء الحكم الإسلامي في العصور الوسطى(58)، وأظهرت الحفريات التي أجريت على الغرف في الطابق الأول (لوحة 9 ) أن القصر بُني على الصخر ، وكان أسفله في العصور القديمة قبل بناء هذا القصر بناء كبير ما زالت أساسات جدرانه مثبتة في أساس القصر (59)، وكذلك يتضح أن القصر كان في الماضي محاطًا بجدار به

${ }^{55}$ ) FӘRHADOĞLU, Kamil : BAKI. İÇəRIŞəHӘR. BAKI, s.116

$\left.{ }^{56}\right)$ Kitabçası, Məlumat : AZӘRBAYCANIN TARIXİ-MEMARLIQ ABİDӘLӘRİ, Şərqiyyə, BAKI - 2008, p.100.

${ }^{57}$ ) FӘRHADOĞLU, Kamil : BAKI. İÇəRIŞəHəR. BAKI, s.116

${ }^{58}$ ) M. Huseynov, L. Bretanitsky, A. Salamzadeh, (History of the Architecture of Azerbaijan). Moscow, 1963.

$\left.{ }^{59}\right)$ M.S. Neymat, Корпус эпиграфических памятников Азербайджана (Azerbaijan`s Epigraphic Monuments), Baku, Elm, 1991. 
أبراج، وبالتالي كان بمثابة المعقل الداخلي لقلعة باكو، وعلى الرغم من ذلك في الوقت الحالي لا توجد آثار لهذا الجدار (60). ومن المعلومات التي اتضحت لنا من خلال الدراسة والبحث للمصادر المختلفة؛ أنه عند بناء القصر كان يحتوي على 52 غرفة ، منها 27 غرفة تقع في الطابق الأول و 25 غرفة تقع في الطابق الثاني(لوحة 10 )(61). البيشطاق(62) يقع في الجدار الغربي للمبنى، حيث تجذب البوابة الرائعة (لوحة7) الانتباه من النظرة الاولي لما تتميز به من زخارف معمارية وهندسية تجمع بين جميع عناصر العمارة الأذربيجانية في القرن الخامس عشر (63). حيث كان مدخل القصر على الجانب الغربي ، من خلال هذه البوابة الضخمة المعقودة (لوحة 7 ) التي تجاوزت ارتفاع القصر في الحجم ، وجدير بالذكر أنه لم تكتمل المنحوتات الحجرية المزخرفة لبوابة القصر في عهد الثيخ إبراهيم ، وقرر خليل الله الاول، في ذكرى والده استكمال الزخارف الرائعة الموجودة عليها تخليدا لذكري والده(64).

$\left.{ }^{60}\right)$ "Palace of the Shirvanshahs". Турагентство в Баку, туры по Азербайджану, туры по Баку. Retrieved 6 June 2018.

${ }^{61)}$ Kitabçası, Məlumat : AZəRBAYCANIN TARIXİ-MEMARLIQ ABIDӘLəRİ, Şərqiyyə, BAKI - 2008, s100.

62 ) البيشطاق: الدذل المؤدي الي لداخل المنشأة أو يتوسط أحد الواجهات الداخلية المطلة علي الصدن، ويتميز

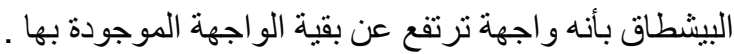

$\left.{ }^{63}\right)$ FӘRHADOĞLU, Kamil : BAKI. İÇӘRIŞつHӘR. BAKI, s.117.

$\left.{ }^{64}\right)$ Ширваншахов, Дворец : Баку, Издательский Дом "Şərq-Qərb ("EastWest")2013,c19. 
وإذا حاولنا أن نصف مدخل القصر من الخارج والذي لازال على حالته حتى الآن، نجده مبني كباقي أبنية مجمع القصر من الحجر الجيري وهو عبارة عن كتلة مرتفعة تبرز قليلاً عن الواجهة، ويتوسطها فتحة دخول ترتفع بارتفاع الواجهة متوجة بعقد مدبب، والداخل منه الي القصر يصعد إليه عبر درج سلم(من خمس درجات) يؤدي الي دركاة بصدرها درجتي سلم يؤديان الي باب الدخول، وعلى جانبي الدركاة دخلتان كل منهما علي شكل إيوان صغير بأسفل كل منهما مصطبة للجلوس، وهو ما اصُطلح عليه (بالمكسلة(65) التي اشتهرت في عمائر العصر المملوكي بمصر(648 - 923هـ / 1250 - 1517م ) (لوحة 15)، أما فتحة الباب فمن الحجر يعلوها عقد مدبب ويحيطها إطار حجري يحدد مساحة الباب، تعلو هذه المساحة في نهاية الجدار من أعلاه، نافذة من الحجر مخرمة للإضاءة والتهوية، مثل جميع نوافذ الطابق الثاني، أما فتحة الباب نفسها فيغلق عليها مصراعين من الخشب، المزين بزخارف نباتية، تفضي فتحة الباب إلى مساحة تعلوها قبة مرتفعة بارتفاع مبنى القصر بطابقيه الأرضي والأول، وهي عبارة عن قبة مبنية من الحجر المرصوص، أو إن جاز التعبير من شبكات من الحجر بها بعض الزخارف الهندسية البسيطة(66). جدران هذه القبة من الداخل قام المعمار بعمل مجموعة من الفتحات

65) المكسلة : هي مسطبة حجرية وجدت علي جانبي حجور المداخل في العمائر المملوكية بشكل خاص، عاصم

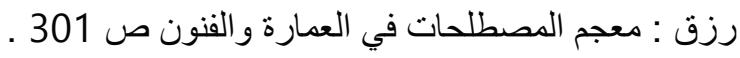

$\left.{ }^{66}\right)$ Kitabçası, Məlumat : AZӘRBAYCANIN TARIXİ-MEMARLIQ ABİDӘLӘRİ, s100. 
المجوفة المصمتة والتي يؤطرها من أعلاها عقود، وهي تثبه في مظهرها وشكلها العام شكل الإيوان (67) لكن بغرض زخرفي وليس وظيفي.

وتفضي المساحة سالفة الذكر من ناحيتها الشمالية الغربية إلى فتحة باب بها درج سلم يؤدي بنا إلي مساحة بها فتحات أبواب تؤدي إلى حجرات الطابق الأرضي، عن طريق عدد من الدهاليز (68)، التي يمكن للإنسان أن يمر من خلالها إلي جميع غرف القصر، أما عن القبة كبيرة الحجم التي تعلوها هذه المساحة، فنجدها ملساء من الداخل خالية من الزخارف، اللهم إلا النوافذ التي تحتوي على شبكات من الحجر

67 ) الإيوان : كلمة فارسية تعني صالة إِتقبال لغة وهو البيت المقبي وهو عبارة عن مساحة مستطيلة

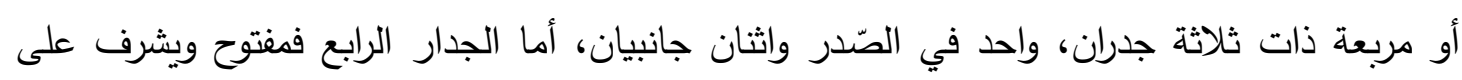

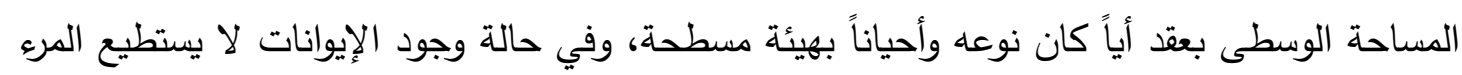
أن ينتقل من إيوان لآخر داخل المنشأة دون استخدام المساحة الوسطى(الصحن) ، صالح لـعي: التراث المعماري الإنلامي في مصر ، ص93.

68 ) الدهليز : بتثديد الدال وكسرها يعني الحنية أو الممر أو الطرقة، فهو ممر أو مكان يصل بين باب المسكن وداخله، أو ما بين الباب والدار • وفي المصطلح الأثري المعماري جاء للدالة على المرر الداخلي الذي يفضي من المبنى إلى الصحن، أو من الردهة التي تلي المدخل الرئيسي إلى الداخل ـأل وقد وصف الدهليز في وثائق العصر المملوكي بعدة أوصاف يتعلق بعضها بشكل عمارته فقيل دهليز مفروش، ودهليز بعضه كثف وبعضه عقودات، بمعنى أن بعضه سماوي بغير سقف وبعضه

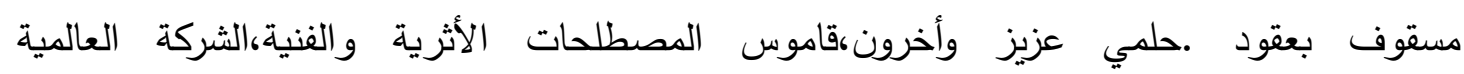
للنشر ،لونجمان، ب9 9 (م،ص73؛ عاصم رزق، معجم مصطلحات العمارة والفنون ص ـ 11 . 
المفرغ للإضاءة والتهوية، فضلا عن شريط زخرفي(إفريز (69)) يلتف حول رقبة القبة بالكامل من الداخل، وهو عبارة عن عقود زخرفية متراصة بجوار بعضها البعض، أسفل هذه القبة في أحد جوانبها لوحة زخرفية منحوتة من الحجر ومثبتة على الجدار تحتوي زخارفها على كتابة باللغة العربية، عبارة عن آية قرآنية من سورة الزلزلة (فَمَنْ

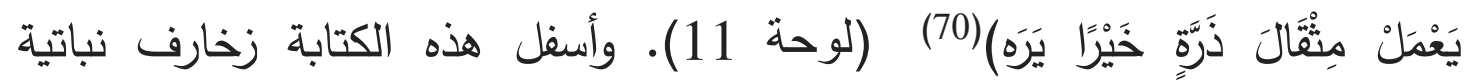
متشابكة(المعروفة بالأرابيسك(71) في الفن الاسلامي) تتوسط هذه الزخارف النباتية شكل مسدس به كلمة(علي) مكررة ثلاث مرات(لوحة 11). أما عن غرف القصر من الداخل فكانت متناظرة، وفي الطابق الثاني ايضا توجد غرف الثاه نفسه وعائلته ، مغطاة بأقبية، والغرف في الطابق السفلي تتميز 69 69 إفريز : هو ما اشرف من الحائط خار جا عنه او ما برز من جدران العمائر والأبنية في هيئه حافه افقيه وهو

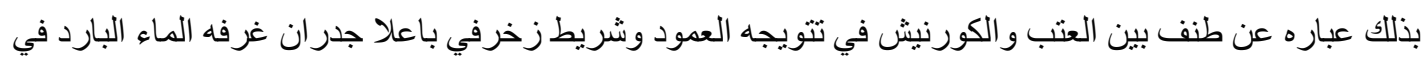

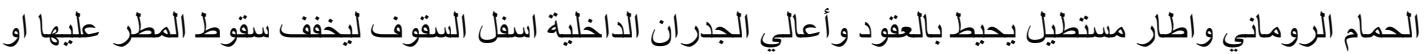

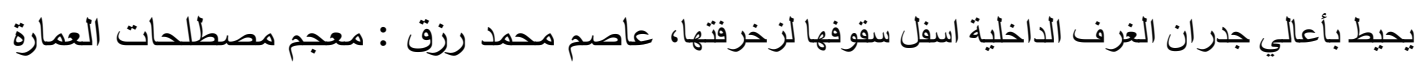
والفنون الإسلامية، مكتبة مدبولي، الطبعة الأولى، القاهرة، 2000م،ص12.

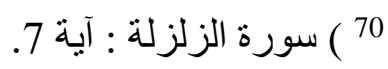

71 )الأرابسك: الذي عرف عند مؤرخي الفنون بعدة أسماء أهمها الرقش والتوشيح والتوريق والعربسة فهو طراز زخرفي ابتداعه العرب بخصائص ومميزات نوعية كانت زخرافها عبارة عن فروع نباتية متشابكة وأغصان متقاطعة وأزهار متدلية لا يعرف الناظر من أين تبدأ ومن أين تتنهي وقد شاعت هذه الزخارف أصلا في الفنون الاسلامية ثم انتقلت منها الي كثير من الفنون الغربية، واتخذت أثكالها النباتية المشار اليها في هيئة حليات متداخلة ومتثابكة، عاصم محمد رزق : معجم مصطلحات العمارة والفنون

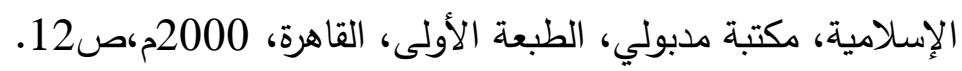


بنوافذ ضيقة تشبه فتحات مزاغل القلاع الحربية(72) ، والتي كانت مخصصة لغرف الخدم(73). أيضا هناك غرف متعددة كانت مخصصة للمرافق والتخزين ، بالإضافة إلى غرف للمشرف المسئول عن أعمال القصر ، وكذلك غرف الخدم ، والحراس ، وشعراء البلاط السلطاني ، والعلماء ، ورجال الدين ، والموسيقيين ، والراقصين ،

72) المزغل : في المصطلح الأثري المعماري فتحة ضيقة في سور الددينة أو القلعة أو الحصن أو البرج أو البوابة تطلق منه الرماح والسهام وغيرها من المقذوفات علي المهاجمين ، كما تستخدم في نفس الوقت للتهوية والإضاءة والمراقبة ، وقد أعتاد المعمار المسلم أن يجعلها ضيقة من الخارج ومتسعة من الداخل ـ عاصم محمد رزق : معجم مصطلحات العمارة والفنون الإسلامية، مكتبة مدبولي، الطبعة

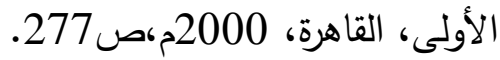

73) FӘRHADOĞLU, Kamil : BAKI. İÇəRIŞəHӘR. BAKI, s.117. 
وعدد كبير من خدم القصر، وغرفة منفصلة تسى "زور خانة"(74)، تستخدم لتمرينات الثاه الرياضية (75). وأما في الطابق العلوي فتتميز الغرف بنوافذ واسعة، وكانت هذه الغرف مخصصًة للعائلة المالكة(76)، حيث توجد غرف خاصة بالثاه وزوجته وأولاده، ومن نوافذ هذه الغرف التي ارتفعت فوق جدران القصر ، يطل على منظر جميل لبانوراما المدينة. ووفقًا لتقاليد البناء في شروان القديمة ، كانت لجميع غرف القصر أسقف مقبية(77)، ومع ذلك فإن الطابق العلوي من القصر لم يحتفظ بهيكله الأصلي الي الان؛ حيث أنه بعد أن أصبحت أذربيجان الثمالية جزءًا من روسيا ، استخدمت 74 )غرفة الزور خانة : كانت الحضارة الإيرانية متفوقة في العديد من المجالات المعمارية والفنية وغيرها مما يشار اليه بالبنان ، وكان أحد أهم هذه الفنون الاجتماعية والمعمارية والرياضية ما يعرف باسم غرفة الزورخانة أحد أهم الأماكن لتثجيع فنون القتال والمصارعة ومعناه بيت القوة ، وقد كان مخصصاً وكما اعتدنا عند دراسه الحضارة والعمارة الايرانيه فإن المبنى الواحد له لتدريب الروح والجسد معا أكثر من وظيفه روحيه ، دينية ، تعليمية ، اجتماعية ، وفنية جماليه وعلى الرغم من ذلك فقد وصلنا من أخبار هذه البيوت الرياضيه أخبار قلة و إن كثرت على لسان المؤرخين والرحاله الأجانب وذلك في القرون الماضية ، الى جانب معرفتنا القليلة عن الفن القتالي الإيراني من خلال المخطوطات الايرانية التي تؤرخ عصور ما قبل الاسلام وا ، أو العبارزات ، ن كانت خطت في العصر الاسلامي

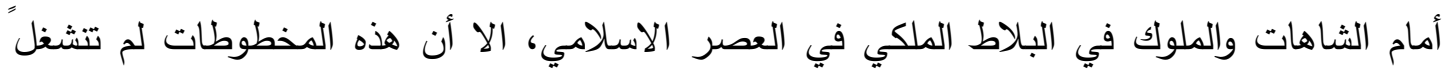
للعديد من الأسباب التي كثيرا بوصف عمارت زورخانه على قدر وصف قوة الفارس وبسالته.

$\left.{ }^{75}\right)$ Ширваншахов, Дворец : Баку, Издательский Дом "Şərq-Qərb ("EastWest")2013,c18.

${ }^{76}$ ) FӘRHADOĞLU, Kamil : BAKI. İÇəRIŞəHӘR. BAKI, s.118.

$\left.{ }^{77}\right)$ Ширваншахов, Дворец : Баку, Издательский Дом "Şərq-Qərb ("EastWest")2013,c18. 
الإدارة العسكرية الروسية مبنى القصر الذي كان منهارًا بسبب الإهمال ، لأغراض حربيه مما أدي الي تدمير العديد من أجزاء ومكونات القصر (78). وتقتح جميع نوافذ الغرف الموجودة في الطابق الثاني على إطلالة جميلة على خليج باكو من خلال فتحات النوافذ الحجرية المميزة لها التي تجعلها أكثر جمالا(79). وعندما بدأت أعمال الترميم الأولى للقصر في 1932-1934م ، لم يكن للمبنى السكني قبة ، حيث كان مغطى بسقف مسطح وذلك بعد التدمير الذي أصاب القبة(80) وكانت الأرضية مصنوعة من الباركيه وأثناء عملية الترميم تمت إزالة الحجارة وتم إصلاح الأرضيات نتيجة للتجديد ، ويوجد حالياً ستة عشر غرفة فقط أصلية في الطابق الثاني منهم القاعة المكونة من ثماني أركان عند المدخل والتي تؤدي إلى هذه الغرف التي لا تزال تحتفظ بمظهرها الأصلي، وكذلك الغرفة المجاور لها، كما أنه تم ترميم الغرف الأربعة عشر المتبقية ، لكنها ليست في نفس القيمة المعمارية للغرف التي لا تزال تحتفظ بشكلها الأصلي من حيث الهندسة المعمارية.

${ }^{78}$ ) Kitabçası, Məlumat : AZORBAYCANIN TARIXİ-MEMARLIQ ABİDӘLӘRİ, p.100.

${ }^{79}$ ) FəRHADOĞLU, Kamil : BAKI. İ̧̧əRIŞəHəR. BAKI, s.117.

80 ) القبة: جمع قباب و قُبب ، وهي بناء مستدير مقوس مجوف يعقد بالأجر و نحوه و خيمة صغيرة أعلاها مستدير ، فالقبة دوران قوس علي محور عمودي ليصبح نصف كرة تقريباً يأخذ مقطعها شكل القوس و تقام مباشرةً فوق مسطح أو ترتفع علي رقبة مضلعة أو علي حنايا ركنية أو مثلثات كروية أو مقرنصات لتحويل الانتقال من المربع إلي المثمن ثم إلي الدائرة. عاصم محمد رزق : معجم مصطلحات العمارة و الفنون الإسلامية ، ص 222 ـ 
وتختلف نقوش الفناء الأمامي للواجهة الرئيسية عن الزخارف الأكثر ثراءً للمباني الداخلية من حيث الأشكال الزخرفية المختلفة كالأرابيسك ، وجودة زخارف الأسطح الملساء للجدران ، وشبكة منقوشة من النوافذ العليا ومداخل النوافذ في الطابق السفلي تعطي تعبيرًا فريدًا لصورة المبنى (81). وأما بالنسبة لسطح القصر تم تجهيزه بأماكن للمراقبة؛ كما هو الحال في تخطيط قلعة شروان القديمة. وكذلك كان هناك إمكانية الوصول إلى السقف من خلال الغرف العلوية؛ حيث يمكنك تتفس الهواء النقي والاسترخاء دون مغادرة مبنى القصر (82)، مما جعل سقف القصر عبارة عن (شرفة)(83) تطل علي البحر مباشرة. أما عن غرفة العرش( لوحة 12) فقد كانت تزينها من أعلاها ثريا(84) مصنوعة من مادة الذهب ، والتي تتكون من اثنتي عشر مصباحاً تصور علامات

1) M.S. Neymat, Корпус: эпиграфических памятников Азербайджана (Azerbaijan’s Epigraphic Monuments), Baku, Elm, 1991.

$\left.{ }^{82}\right)$ Ширваншахов, Дворец : Баку, Издательский Дом "Şərq-Qərb ("EastWest")2013,c19.

3 )(الثرفة: جمع شرافات أو شراريف وهي نهاية الثيء من حافته وقد استخدمت للالالة علي ما يوضع أعالي القصور وأسوار المدن وواجهات المساجد وغيرها من المباني، عاصم محمد رزق : معجم مصطلحات العمارة والفنون الإسلامية ، ص 161 .

1) الثريا: هي أداه من أدوات الإضاءة المعننية تثتمل عادة علي عدة مصابيح ، ومن المعروف أن الثريا كانت وسيلة الاضاءة التي تعلق في السقف المراد إضاءته فيها عدة سرج أو قناديل بلورية أو نحاسية أو غير ذلك من المواد، وكانت من عادة منشئي الأثار الإنلامية من السساجد والمدارس والخانقاة والقباب وغيرها أن يزود هذه الأبنية الي جانب القناديل والتتانير بالثريات الكبيرة والصغيرة لإضاءتها، عاصم محمد رزق : معجم مصطلحات العمارة والفنون الإسلامية ، ص 62. 
البروج ، ذات جمال خاص، يصفها شاعر البلاط بدر شرواني متحدثا عن اتقان صنعتها في قصيدته

" إنها مثل علامة البروج السماوي، تبدو وكأنها حركة الثمس فوق قوس السماء، انظر إلى هذين الدجالين المعلقين تحت الهيكل، رأس واحد لأسفل والآخر لأعلى مثل القبة " (85)، وتعتبر غرفة العرش من أجمل الغرف لما احتوت عليه من كنوز ملكية وآثار زخرفية، وقد تم نهب الكثير منها بعد هجمات الدولة العثمانية ثم الغزو الروسي(86)، وقد كان يُستقبل في غرفة العرش كبار ضيوف الدولة من الأمراء والمبعوثين الدبلوماسيين الزائرين لعاصمة البلاد(87)

وبشكل عام فإن المبنى من الداخل عادة ما يكون سابحا في ضوء النهار المنتثر بشكل لافت؛ وذلك لكثرة النوافذ والابواب التي تحيط به من كل جانب، وتتميز القاعة الملكية بمساحتها الواسعة ونظام الإضاءة الطبيعية خاصة اثناء النهار وذلك لكثرة الابواب والنوافذ والقباب المفتوحة. كما يتميز المبنى بطرازه المعماري الاسلامي؛ حيث تنتشر الاعمدة والعقود التي تعطيه مسحة جمالية وتمنحه روعة وتنرد (88).

$\left.{ }^{85}\right)$ Ширваншахов, Дворец : Баку, Издательский Дом "Şərq-Qərb ("EastWest")2013,c20.

2) M. Huseynov, L. Bretanitsky, A: Salamzadeh, (History of the Architecture of Azerbaijan). Moscow, 1963

87) С. ДАДАШЕВ и М. УСЕЙНОВ: АРХИТЕКТУРНЫЕ ПАМЯТНИКИ БАКУ, БАКУ , 1955 ,с26.

${ }^{88}$ ) "Palace of the Shirvanshahs". Турагентство в Баку, туры по Азербайджану. 
وختاما فإن ظاهرة طول عمر قصر شروان شاه لتثير الدهشة ، حيث يفترض التدمير الإجباري لمقر العدو المهزوم على يد تيمور لنك(89) الذي حاول بعد استيلائه علي شروان أن يمحو القصر من الذاكرة ، ولكن جاء بعده العديد من هؤلاء الفاتحين في تاريخ شروان؛ الذين قاموا بإعادة بناء مباني القصر وأستخدمه في أغراض مختلفة وهذا سر تواجد القصر حتى يومنا هذا (90.

\section{الخاتمة وتتضمن أهم النتائج و التوصيات:

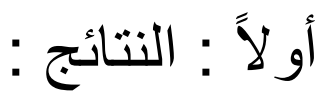

• تعتبر فترة حكم دولة شروان شاه من أهم الفترات في تاريخ أذربيجان من الناحية الاقتصادية والسياسية والاجتماعية، فضلا عن النواحي المعمارية والفنية.

89 ) تيمور لنك : يعتبر تيمورلنك المؤسس الحقيقي للدولة التيمورية التي حكمت إيران ما يقرب من قرن ونصف القرن من الزمان ( 771 - 911هـ / 1371 - 1504م ) ، واشتهر بالقسوة والوحشية وسفك

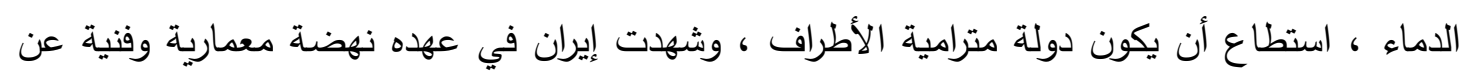

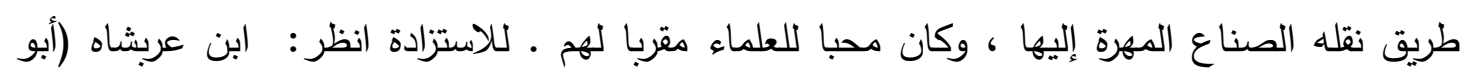
محمد أحمد بن محمد بن عبدالله الدمثقي ت 854هـ) : عجائب المقدور في نوائب تيمور ، تحقيق

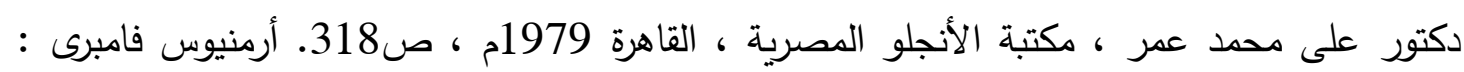
تاريخ بخاري منذ أقدم العصور حتى العصر الحاضر ، ترجمة أحمد محمود الساداتى ، الطبعة الثانية

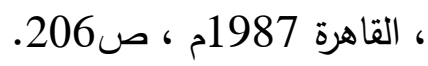

$\left.{ }^{90}\right)$ Ширваншахов, Дворец : Баку, Издательский Дом "Şərq-Qərb ("EastWest")2013,c22. 
توصلت الدراسة إلى أن مدينة باكو كانت واحدة من أقدم المدن وأكثرها ثقافة في العالم، وارتبطت تاريخيا وجغرافيا بالعديد من دول العالم المختلفة، ولعبت بموقعها الجغرافي دوراً كبيراً في الحياة الاقتصادية والسياسية والثقافية لشعوب دول شرق ووسط أسيا لعدة قرون ؛ مما يؤكد علي أهمية هذه المدينة تاريخيا وجغرافيا خلال

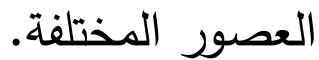
• استطاعت الدراسة أن تؤكد أن باكو مدينةٌ متمازجة الثقافة، ولكن المعالم الأهم ذات الطابع الإسلامي الثرقي مثل قصر شروان شاه. • لعب قصر شروان شاه دورا كبيرا في الازدهار الحقيقي لدولة شروان شاه؛ وهذا مما جعله دائما يتعرض لسلسلة من التجديدات والاضافات من قبل الدولة. أماطت الدراسة اللثام عن أن سبب التتاغم والاكتمال المعماري لقصر شروان كان نتيجة طبيعية لمشاركة أفضل المهندسين المعماريين والمهندسين الفنيين والبنائين والنحاتين والخطاطين من جميع أنحاء شروان في تثييده وبناءه. • تم بناء جميع مباني مجمع قصر شروان شاه من حجر اللوز المحلي ، وهو الحجر الجيري؛ و يعد المصطلح المعماري والمتعلق بالبناء "حجر اللوز الجيري"، أحد المصطلحات الاثرية الدارجة في هذا القطر . يتضح أن القرن الخامس عشر الميلادي فترة إحياء اقتصادي وثقافي لدولة شروان؛ حيث أن هذه الفترة كانت فترة سلام وهدوء لدولة شروان ومن ث كان هناك تقدم كبير في الفن والهندسة المعمارية والتجارة وغيرها من الانثطة. 
• لم يتم بناء قصر شروان وفقا لخطة معمارية واحدة، وعلى الرغم من ذلك لا يتعارض أحد المباني مع الآخر، بل علي العكس من ذلك تجد أحدهما يقوم

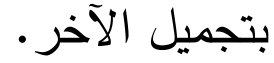

ربطت الدراسة بين استخدام بعض العناصر المعمارية الثهيرة في العصر المملوكي في مصر كالمكسلة وغيرها ووجودها بقصر شروان شاه. • لعبت اللغة العربية دورا مهما من خلال تسجيل النقوش الكتابية بها، على آثار الدراسة، واتضح ذلك جليا من خلال استخدامها في جميع الكتابات والنقوش داخل مجمع قصر شروان شاه . • كان لكثرة الابواب والنوافذ والقباب المفتوحة بقصر شروان أن تم الاعتماد عليها كنظام إضاءة طبيعية خاصة اثناء فترات النهار . • كان لتكرار استخدام القصر من خلال الدول التي حكمت أذبيجان سببا في بقاءه على حالته حتي يومنا هذا.

\section{ثانياً : توصيات الدر اسة :}

العمل علي الاستفادة من القصور التاريخية الأثرية في مجال السياحة

$$
\text { والترويج لها عالمياً. }
$$

إعادة استخدام القصور التاريخية من خلال استخدامها قصور متحفيه .

$$
\text { المصادر و المر اجع العربية : }
$$


1. ابن عربشاه (أبو محمد أحمد بن محمد بن عبدالله الدمشقي ت 854هـ) : عجائب المقدور في نوائب تيمور ، تحقيق دكتور على محمد عمر ، مكتبة الأنجلو المصرية ، القاهرة 1979م •

2. أرمنيوس فامبرى : تاريخ بخاري منذ أقدم العصور حتى العصر الحاضر ، ترجمة أحمد محمود الساداتى ، الطبعة الثانية ، القاهرة 1987م. 3. جلال خشيب: إقليم ناغورنوكاراباخ... بين الإرث التاريخي القوقازي والحسابات الإقليمية التركية- الإيرانية، مجلة رؤية، جامعة مرمرة، تركيا. (2-

$$
\text { 5)، صيف 2016م. }
$$

4. حسن الباشا: الألقاب الإسلامية في التاريخ والوثائق والاثار، الدار الفنية للنشر والتوزيع، القاهرة، 1989م. 5. حلمي عزيز وأخرون: قاموس المصطلحات الأثرية والفنية ،الثركة العالمية للنشر كلونجمان، بr 999 (م. 6. زامباور: معجم الأنساب والأسرات الحاكمة في التاريخ الإسلامي، أخرجه زكي محمد حس، حسن أحمد محمود، دار الرائد العربي، بيرروت-لبنان، 1400هـ 1980م 7. سامي محمد نوار: الكامل في مصطلحات العمارة الإسلامية من بطون المعاجم اللغوية، دار الوفاء، القاهرة، 2002م. 8. سعيد عبدالفتاح عاشور : العلاقات العربية الإيرانية من الفتح الإسلامي حتى

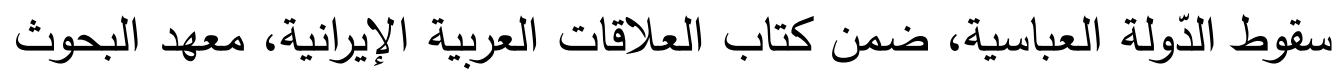
والدراسات العربية، القاهرة، 1993م. 
9. صالح كَلَنْ: سلاطين الدولة العثمانية، ترجمة منى جمال الدين، القاهرة، دار النيل للطباعة والنشر ، 1435هـ/2014م.

صالح لمعي: التراث المعماري الإسلامي في مصر، دار

النهضة العربية للطباعة والنشر والتوزيع، القاهرة .

عاصم محمد رزق : معجم مصطلحات العمارة والفنون

الإسلامية، مكتبة مدبولي، الطبعة الأولى، القاهرة، 2000م.

12. عز تلو يوسف بك آصاف : صفحات من تاريخ مصر ( تاريخ

سلاطين بنى عثمان من أول نشأتهم حتى الآن ) ، مكتبة مدبولى ، القاهرة .

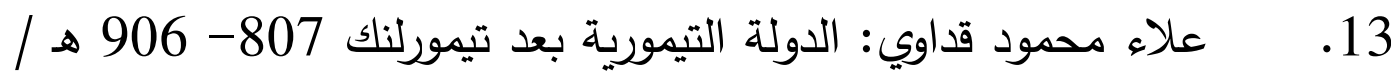

1405- 1500 م : دراسة سياسية، مجلة كلية الانسانيات والعلوم

الاجتماعية، العدد الثاني والعشرين، 1420هـ/1999م.

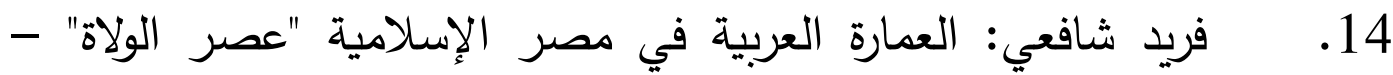
الجزء الأول ، الهيئة المصرية العامة للكتاب، القاهرة، 1994م.

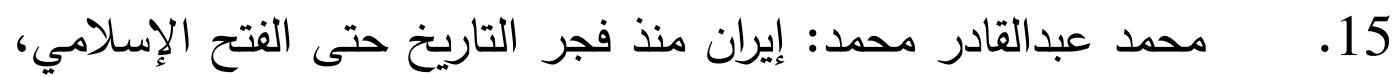

مكتبة الأنجلو المصرية، الطبعة الأولى، القاهرة، 1982م.

16. ياقوت الحموي(الثيخ الإمام شهاب الدين أبي عبدالله ياقوت بن عبدالله الحموي الرومي البغدادي ت:626هـ) : معجم البُلدان، دار صادر، بيروت، 1397هـ/1977م، المجلد الثالث. 


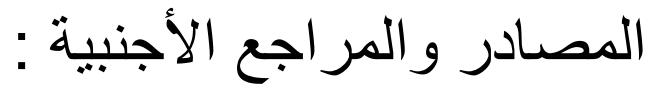

1- Ахундов Д. А , Архитектура древнего и раннесредневекового Азербайджана , ,Баку , Азернешр, 1986 .

2- Азернешр, История Баку сквозь века. Султанова БАКУ,1992.

3- Bünyadov T.A. Azərbaycan arxeologiyası oçerkləri. Bakı, Azəməşr, 1960.

4- С. ДАДАШЕВ и М. УСЕЙНОВ: АРХИТЕКТУРНЫЕ ПАМЯТНИКИ БАКУ, БАКУ , 1955 .

5- Dilgam Yunis Ismailov:History of Azerbaijan, Azmiu npm,Baku, 2017.

6- FӘRHADOĞLU, Kamil : BAKI. İÇəRIŞӘHӘR. BAKI, "Ş-Q" \& "ÇİNAR-ÇAP", 2006.

7- Kitabçası, Məlumat : AZӘRBAYCANIN TARIXİ-MEMARLIQ ABIDDLӘRİ, Şərqiyyə, BAKI - 2008.

8- M. Huseynov, L. Bretanitsky, A: Salamzadeh, (History of the Architecture of Azerbaijan). Moscow, 1963.

9- M.S. Neymat, Корпус эпиграфических памятников Азербайджана (Azerbaijan's Epigraphic Monuments), Baku, Elm, 1991.

10- "Palace of the Shirvanshahs". Турагентство в Баку, туры по Азербайджану, туры по Баку. Retrieved 6 June 2018.

11- Искендер Тагиев: Дворец Ширваншахов или Ханака С.Я.Бакув, ÇAŞIOĞLU ,Баку ,2003.

12- Левиатов В.Н. Археологические раскопки 1945 года при Ширваншахов в городе Баку. Изв.АН Азерб.ССР, № 1, 1948.

13- Лейла Рахманов : Музеи, заповедники, галереи Баку (пособие для туристов) , Баку ,2015 .

14- Ширваншахов, Дворец : Баку, Издательский Дом “ŞərqQərb ("East-West"), 2013. 


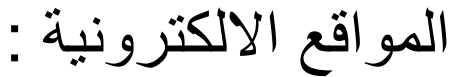

1. https://president.az/president/biography.

2. https://icherisheher.gov.az/az/93-sirvansahlar-saray-kompleksi/ 